\title{
Two-Dimensional Nanomaterials for Boosting the Performance of Organic Solar Cells
}

\author{
Zhenbang Wei ${ }^{\dagger}$, Langkun Chen ${ }^{\dagger}$, Kunzhu Liu, Shenghua Liu $* \mathbb{D}$, Xiangguo Li, Qian Zhang and Jing Shuai
}

check for updates

Citation: Wei, Z.; Chen, L.; Liu, K.; Liu, S.; Li, X.; Zhang, Q.; Shuai, J.

Two-Dimensional Nanomaterials for Boosting the Performance of Organic Solar Cells. Coatings 2021, 11, 1530. https://doi.org/10.3390/ coatings 11121530

Academic Editor: Vera Marinova

Received: 20 November 2021 Accepted: 9 December 2021 Published: 13 December 2021

Publisher's Note: MDPI stays neutral with regard to jurisdictional claims in published maps and institutional affiliations.

Copyright: (c) 2021 by the authors. Licensee MDPI, Basel, Switzerland. This article is an open access article distributed under the terms and conditions of the Creative Commons Attribution (CC BY) license (https:// creativecommons.org/licenses/by/ $4.0 /)$.
School of Materials, Shenzhen Campus of Sun Yat-sen University, No. 66, Gongchang Road, Guangming District, Shenzhen 518107, China; weizhb@mail2.sysu.edu.cn (Z.W.); chenlangkunclk@163.com (L.C.); ross_lau@163.com (K.L.); lixguo@mail.sysu.edu.cn (X.L.); zhangqian6@mail.sysu.edu.cn (Q.Z.); shuaij3@mail.sysu.edu.cn (J.S.)

* Correspondence: liushengh@mail.sysu.edu.cn

t The authors are contributed equally.

Abstract: The thin-film organic solar cells (OSCs) are currently one of the most promising photovoltaic technologies to effectively harvest the solar energy due to their attractive features of mechanical flexibility, light weight, low-cost manufacturing, and solution-processed large-scale fabrication, etc. However, the relative insufficient light absorption, short exciton diffusion distance, and low carrier mobility of the OSCs determine the power conversion efficiency (PCE) of the devices are relatively lower than their inorganic photovoltaic counterparts. To conquer the challenges, the two-dimensional (2D) nanomaterials, which have excellent photoelectric properties, tunable energy band structure, and solvent compatibility etc., exhibit the great potential to enhance the performance of the OSCs. In this review, we summarize the most recent successful applications of the 2D materials, including graphene, black phosphorus, transition metal dichalcogenides, and $\mathrm{g}-\mathrm{C}_{3} \mathrm{~N}_{4}$, etc., adapted in the charge transporting layer, the active layer, and the electrode of the OSCs, respectively, for boosting the PCE and stability of the devices. The strengths and weaknesses of the 2D materials in the application of OSCs are also reviewed in details. Additionally, the challenges, commercialization potentials, and prospects for the further development of 2D materials-based OSCs are outlined in the end.

Keywords: organic solar cells; 2D materials; additives; active layer; charge transporting layer

\section{Introduction}

Globe environment pollution and energy crisis have become the major issues accompanied with the economic growth owing to the excessive consumption of fossil resources. Searching for alternative renewable energy is one of the most significant technologies to solve the urgent problems [1,2]. Solar energy has become an ideal energy resource due to its inexhaustible, widespread, and environmentally friendly characteristics, which can be effectively exploited and converted into electricity [3-6]. Organic solar cells (OSCs) as one of the third-generation photovoltaics have achieved rapid development currently, which exhibit great advantages for their low cost, light weight, simple manufacture, and large-area fabrication [7-9]. In recent years, the performance of the OSCs has been dramatically improved with the emergence of the non-fullerene acceptor and the relevant donor materials [7,10-15], which leads to the tremendous breakthroughs in power conversion efficiencies (PCE) of the OSCs. According to the theoretical calculations, it is reported the highest efficiency of the single-junction non-fullerene acceptor-based OSCs (NFA-OSCs) is expected to exceed 20\% [16-21]. However, the NFA-OSCs are still confronted with several challenges compared with other high-efficient photovoltaics. Particularly, the relatively low device efficiency and long-term instability of the OSCs limit their industrial production and commercialization [22-24]. The serious electron-hole recombination, low carrier mobility of the active layers, and insufficient sunlight absorption are taking the main responsibility for the limited PCE of the OSCs. Besides, it is well acknowledged that the most commonly used hole 
transport layer (HTL) material, Poly(3,4-ethylenedioxythiophene):poly(styrenesulfonate) (PEDOT:PSS) exhibits hygroscopicity characteristic, which can easily corrode the indium tin oxide (ITO) electrode material, decreasing the efficiency and stability of the devices [25-29].

Lots of strategies have been applied to improve the efficiency and stability of the OSCs $[4,11,12,18]$. For example, the introduction of metal nanostructures into the OSCs can increase the light absorption capacity of the active layer with a plasma enhancement effect [30-32], increasing the PCE of photovoltaic devices. Owing to the quantum size effect, the addition of quantum dots into the active layer of the OSCs can harvest more sunlight from the wider band of the solar spectrum for enhancing the efficiency of the devices [33-36]. Nanowires with conductive properties can replace ITO as electrode materials of the OSCs with superior stability and competitive photovoltaic performances [37-41].

Among the variety of the nanomaterials applied in the OSCs, 2D layered materials can be considered as promising candidates for the application in different positions of the OSCs due to their excellent optoelectronic characteristics, tunable energy band structure, and relatively stable physical and chemical properties [42-48]. Most of the 2D nanomaterials have a typical layered structures with solution-processability $[6,25,26,38,44,45]$. In Table 1 , we list a few typical 2D materials and their key physical parameters. The 2D materials, such as $\mathrm{WSe}_{2}$, BP, etc. with tunable bandgaps exhibit carrier mobilities several orders of magnitude higher than those of the organic semiconductors in OSCs.

Table 1. The physical parameters of a few novel 2D materials applied in OSCs.

\begin{tabular}{cccc}
\hline Materials & Bandgap $\mathbf{( e V )}$ & $\begin{array}{c}\text { Carrier Mobility } \\
\left(\mathbf{c m}^{\mathbf{2}} \mathbf{~} \mathbf{~}^{-\mathbf{1}} \mathbf{s}^{-\mathbf{1}} \mathbf{)}\right.\end{array}$ & Ref. \\
\hline $\mathrm{WSe}_{2}$ & $1.2-1.7$ & 500 & {$[49]$} \\
$\mathrm{MoSe}_{2}$ & 1.5 & 50 & {$[50]$} \\
$\mathrm{Bi}_{2} \mathrm{O}_{2} \mathrm{~S}$ & 1.27 & $16,000-26,000$ & {$[51]$} \\
$\alpha-\mathrm{In}_{2} \mathrm{Se}_{3}$ & $1.5-2.8$ & 2.5 & {$[52]$} \\
$\mathrm{BP}$ & $0.3-2.0$ & 1000 & {$[53]$} \\
$\mathrm{Ti}_{3} \mathrm{C}_{2} \mathrm{~T}_{\mathrm{x}}$ & $0-3.4$ & 0.70 & {$[54]$} \\
$\mathrm{Graphene}^{\mathrm{M} h}$ & 0 & 1000 & {$[55]$} \\
$\mathrm{MoS}_{2}$ & $1.2-1.8$ & $10-200$ & {$[56]$} \\
\hline
\end{tabular}

The incorporation of suitable 2D materials into the OSCs, not only can enhance the light absorption and scattering in the devices, but also improve the charge transport and suppress the carrier recombination, leading to an enhancement of PCE with the increased fill factor (FF) and short-circuit current density (Jsc) of the OSCs. Besides, appropriate 2D materials can replace the unstable PEDOT:PSS layer or evaporated electrodes for improving the stability and simplifying the fabrication process of the OSCs.

In this review, we summarize a series of novel 2D materials applied in the active layer, $\mathrm{HTL}$, and the electron transport layer (ETL), as well as the electrode in the OSCs to enhance the efficiency and stability of the devices, including graphene and its derivatives, transition metal dichalcogenides (TMDs), and black phosphorus (BP), etc. Ultimately, the challenges and the commercialization prospects for the further development of OSCs based on 2D layered materials are also discussed.

\section{The Application of 2D Materials in the Active Layer}

To achieve high-performance OSCs, 2D materials involved in the active layer of the photovoltaic devices as the third components have aroused widespread concerns. Graphene has attracted tremendous attention since being synthesized in 2004 [57], which possess excellent carrier mobility. And its derivative graphene oxide (GO) by solutionprocessable exfoliation of graphene has also been extensively studied in the field of organic optoelectronic devices due to the high carrier mobility, great conductivity, and solution dispersibility at the presence of oxygen functional groups [58-62]. In 2015, Stylianakis et al. synthesized the graphene-based porphyrin molecule (GO-TPP) as an additive in the active 
layer of OSCs [63]. Simply by covalent interaction between the GO and 5-(4-aminophenyl)$10,15,20$-triphenyl) porphyrin (TPP- $\mathrm{NH}_{2}$ ) as shown in Figure $1 \mathrm{a}$, the TPP- $\mathrm{NH}_{2}$ porphyrin presents $\pi$ aromatic framework with excellent stability and light-harvesting capacity. As presented in Figure 1b, the OSCs based on PCDTBT:PC ${ }_{71} B M$ and PTB7:PC 71 BM were fabricated, respectively, which exhibited the device structure of ITO/PEDOT:PSS/Active layer + GO-TTP $/ \mathrm{TiO}_{x} / \mathrm{Ca} / \mathrm{Al}$. The incorporation of GO-TPP enabled to optimize the band structure of the device with cascaded energy levels between the donor and acceptor as shown in Figure 1c. Moreover, it provided continuous penetration paths between the donor and acceptor interfaces, which led to the suppression of exciton recombination and the promotion of charge transport. As shown in Figure 1d,e. The best PCEs of 7.13\% and $8.81 \%$ in the PCDTBT:PC 71 BM and PTB7:PC 71 BM-based OSCs were achieved, respectively by adding the optimum concentration of $0.3 \%$ GO-TPP.

(a)

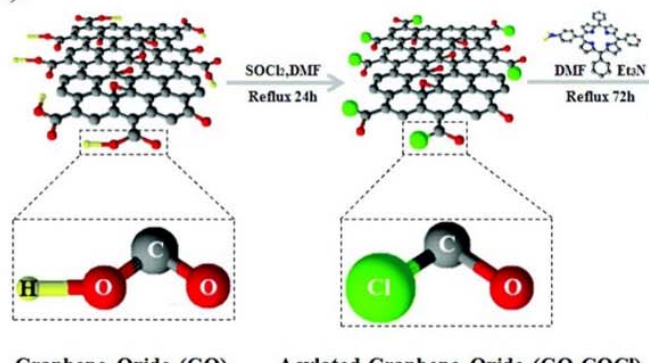

(c)

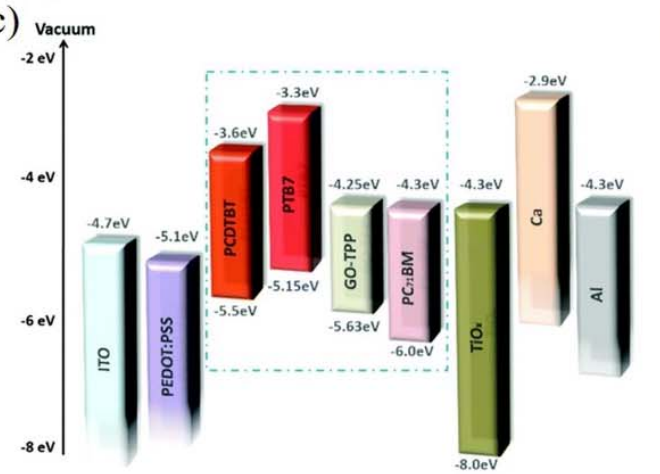

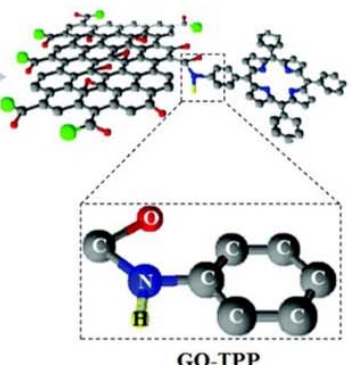

(d)

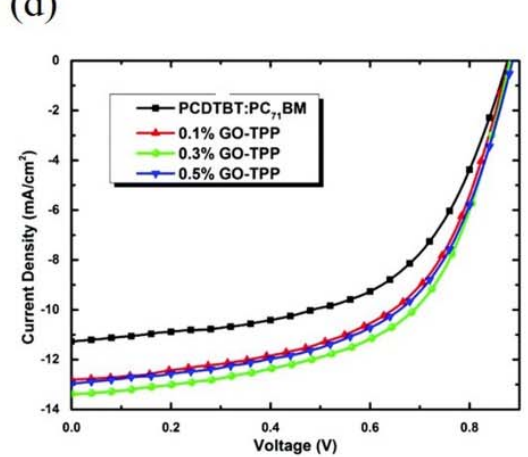

(b)

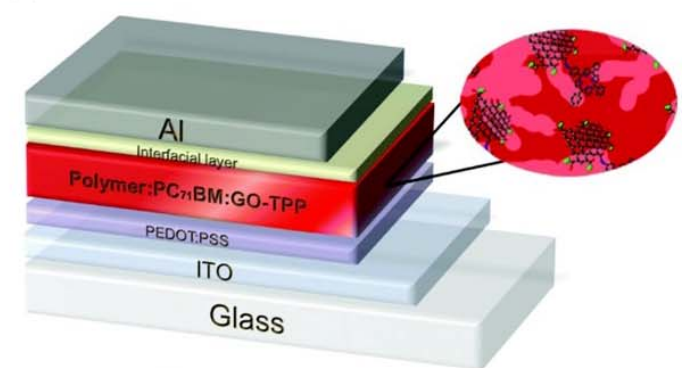

(e)

Figure 1. Schematic representation of (a) the chemical synthesis of GO-TPP and (b) the photovoltaic device; (c) Energy level

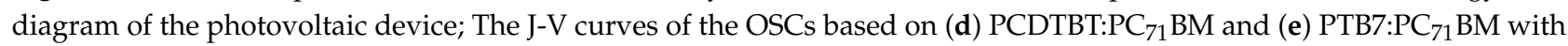
different concentrations of GO-TPP. Reprinted with permission from [63]. Copyright 2015 The Royal Society of Chemistry.

Among the variety of 2D nanomaterials, besides graphene and its derivatives, transition metal dichalcogenides (TMDs) are the most widely studied materials, which are formed by the transition metal atom such as $\mathrm{W}, \mathrm{Mo}, \mathrm{Pd}$, Pt et al. sandwiched among the chalcogenide atoms such as Se, S, Te. TMDs like $\mathrm{WSe}_{2}$ that have been studied in the early, exhibits high mobility around $500 \mathrm{~cm}^{2} \mathrm{~V}^{-1} \mathrm{~s}^{-1}$ and $10^{4} \mathrm{on} /$ off ratios at $60 \mathrm{k} . \mathrm{MoS}_{2}$ is also a popular TMD material with high mobility of $200 \mathrm{~cm}^{2} \mathrm{~V}^{-1} \mathrm{~s}^{-1}$ at room temperature. The bandgap of $2 \mathrm{DWS}_{2}$ is more than $2 \mathrm{eV}$, while the $2 \mathrm{D} \mathrm{MoS}_{2}$ is approximately $1.2-1.9 \mathrm{eV}$. The TMDs with different thicknesses related to the nanoscale domain sizes of the active layer have distinctly different effects on the performance of the OSCs.

In 2017, Kymakis et al. incorporated WSe $e_{2}$ flakes into the active layer of PTB7:PC 71 BMbased OSCs [64]. As shown in Figure 2a. They exploited the sedimentation-based separation to sort the $\mathrm{WSe}_{2}$ flakes by ultracentrifugation with different centrifugal speeds, which obtained different sizes of $\mathrm{WSe}_{2}$ with $\sim 70, \sim 240$, and $\sim 720 \mathrm{~nm}^{2}$, respectively (see Figure $2 \mathrm{~b}-\mathrm{d}$ ). The structure of the device based on PTB7:PC ${ }_{71} \mathrm{BM}: W \mathrm{We}_{2}$ was displayed in Figure 2e. The bandgap of $\mathrm{WSe}_{2}$ could be tuned with the thickness variation from $0.8 \mathrm{eV}$ in the bulk to $1.3 \mathrm{eV}$ in the single layer, which provides matchable energy levels to 
improve the carrier mobility, exciton dissociation, and charge extraction (seen in Figure 2f). It is demonstrated that the incorporation of $\mathrm{WSe}_{2}$ flakes with a similar size to the domain of the active layer led to the best PCE $s$ for the OSCs due to the optimized percolation pathways for charge transport. Therefore, the champion devices based on PTB7:PC ${ }_{71} \mathrm{BM}$ with the incorporation of $\sim 240 \mathrm{~nm}^{2} \mathrm{WSe}_{2}$ achieved the PCE of $9.45 \%$, enhancing by $16.67 \%$ compared with the control devices, as shown in Figure $2 \mathrm{~g}$. This research quantitatively illustrated the relationship between the 2D nanomaterial and domain sizes of the active layer, indicating the effective strategy to control the area and thickness of the 2D materials for improving the photovoltaic performance of the OSCs and other photovoltaics.

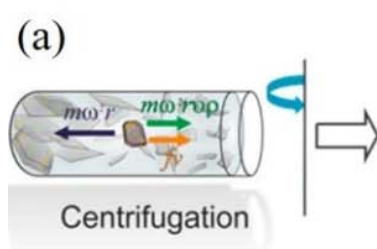

(e)

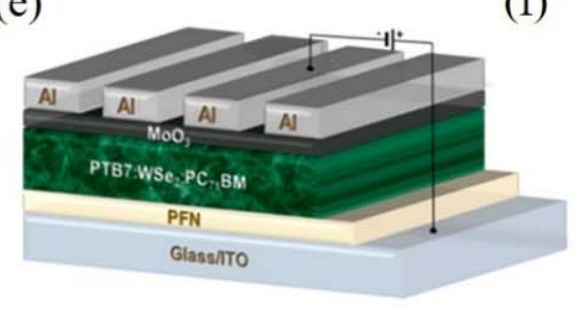

(f)
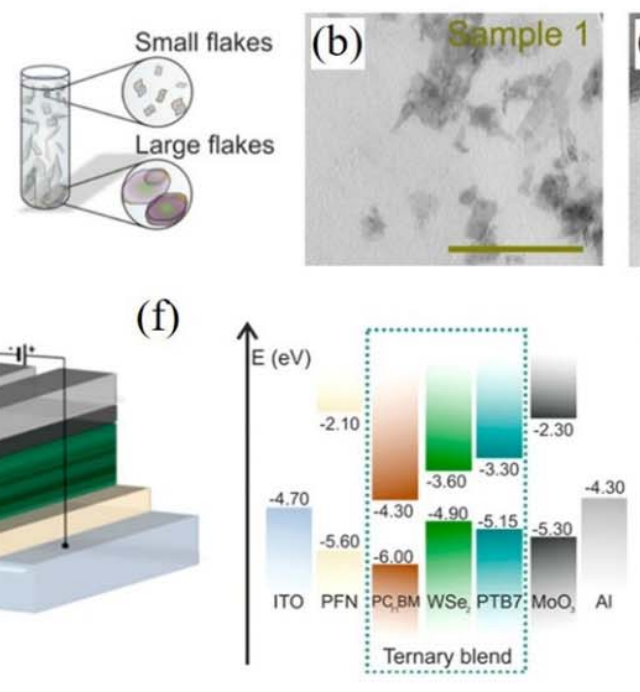
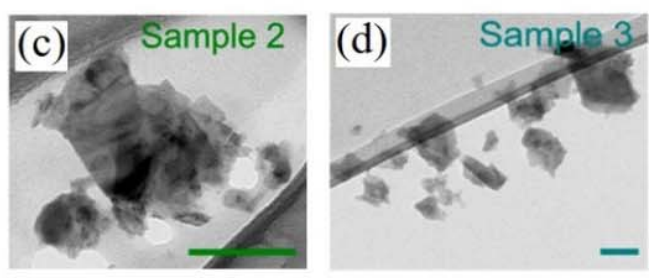

(g)

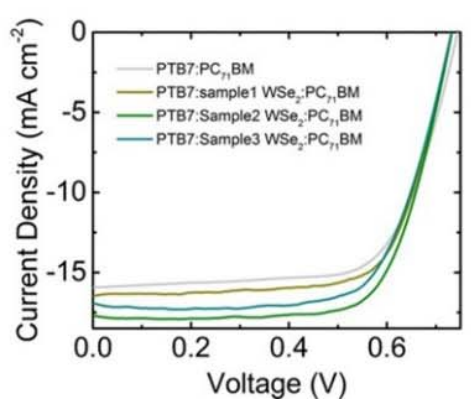

Figure 2. Schematic representation of (a) the fabrication of $\mathrm{WSe}_{2}$ flakes by ultracentrifugation depended on SBS method and the separation of different sizes of WSe ${ }_{2}$ flakes; TEM images of $W_{S e}$ flakes with different area values of (b) 70 , (c) 240 and (d) $\sim 720 \mathrm{~nm}^{2}$, respectively; (e) The device structure of ternary OSCs with incorporation of WSe ${ }_{2}$ flakes in the active layer; (f) Schematic energy levels and (g) J-V curves of the OSCs based on PTB7:PC 71 BM. Reprinted with permission form [64]. Copyright 2017 American Chemical Society.

To further enrich the application of 2D TMDs materials in the OSCs, it is of necessity to exploit new methods for the functionalization of TMDs materials. In 2019, Wei et al. adopted the hydrogen plasma treatment to modify the properties of $\mathrm{MoSe}_{2}$ as shown in Figure 3a [65]. Hydrogenated $\mathrm{MoSe}_{2}$ nanosheets will form the H-Se-Mo bonds, which can lead to the electron transfer from the hydrogen atoms to the selenium atoms, enhancing the repulsive forces among selenium atoms and increasing the quantities of the produced photoelectrons. Hydrogenated $\mathrm{MoSe}_{2}$ was subsequently applied in the OSCs based on PTB7-Th:PC ${ }_{71} \mathrm{BM}$ in the active layer as displayed in Figure $3 \mathrm{~b}$. The incorporation of hydrogenated $\mathrm{MoSe}_{2}$ in the ternary blend optimized the morphology of the active layer and served as additional conducting bridges for the charge transfer, improving the carrier mobility in the devices (seen in Figure 3c). As shown in Figure 3d,e, the champion devices based on PTB7-Th:PC 71 BM and PBDTTBOIT- 4 F reached $10.44 \%$ and $8.13 \%$, respectively by incorporating the hydrogen plasma-treated $\mathrm{MoSe}_{2}$ nanosheets in the active layer. Moreover, hydrogenated TMDs show great stability owing to the shorter bonding distance between the chalcogen atoms and hydrogen atoms than those between the chalcogen atoms and other atoms from density functional theory calculations. Thus, after thermal treatment at $100{ }^{\circ} \mathrm{C}$ for $1 \mathrm{~h}$, the devices with the hydrogenated $\mathrm{MoSe}_{2}$ maintained $70 \%$ of the original PCE compared with the reference devices with $60 \%$, as exhibited in Figure $3 f$. 
(a)

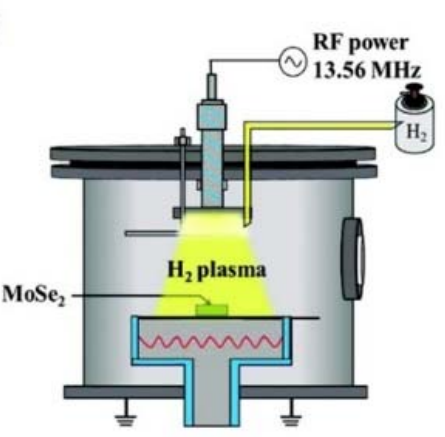

(d)

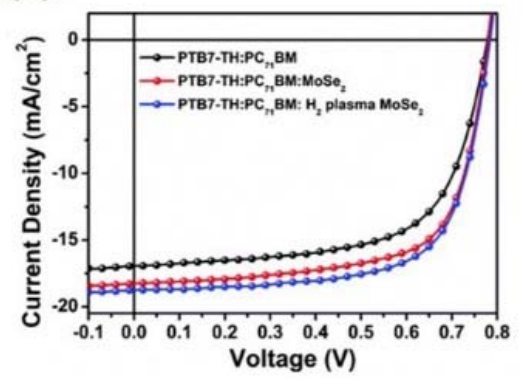

(b)

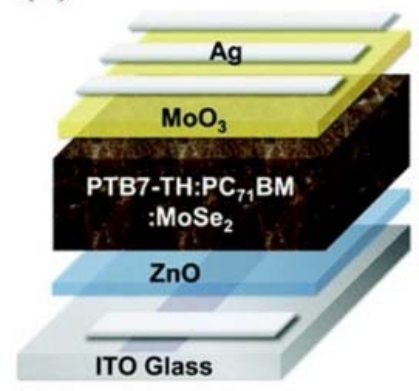

(e)

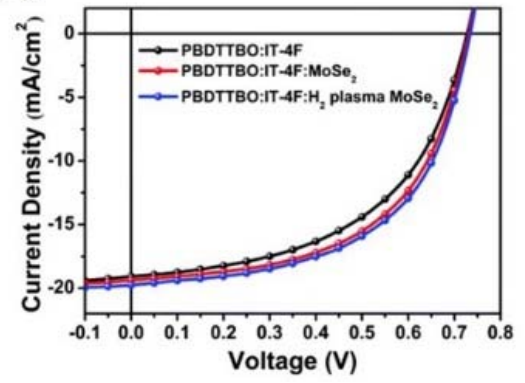

(c)

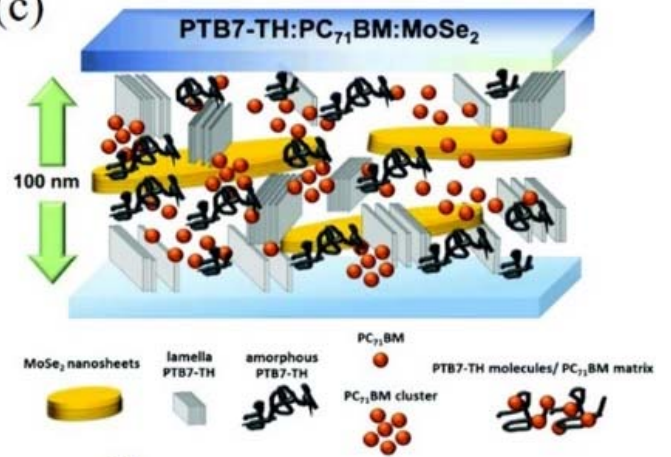

(f)

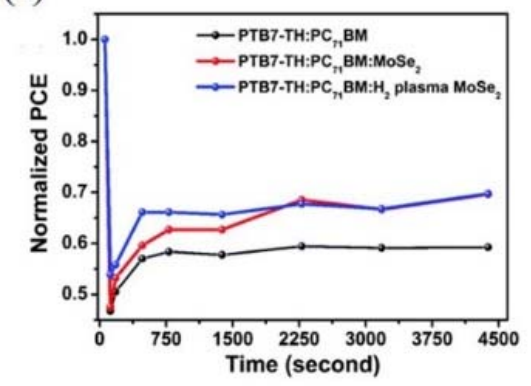

Figure 3. (a) Schematic representation of the $\mathrm{H}_{2}$ plasma treatment; (b) The device structure of inverted OSCs based on PTB7Th:PC ${ }_{71} \mathrm{BM}$ with $\mathrm{MoSe}_{2}$; (c) Schematic diagram of the interplay of MoSe 2 with PTB7-TH and PC 71 BM; J-V characteristics of (d) PTB7-Th:PC 71 BM and (e) PBDTTBO:IT-4F devices without $\mathrm{MoSe}_{2}$ and introducing MoSe 2 with and without hydrogen plasma treatment; (f) Stability of PCE values of devices based on PTB7-TH:PC 71 BM without MoSe 2 and adding MoSe 2 with and without hydrogen plasma treatment at $100{ }^{\circ} \mathrm{C}$. Reprinted with permission form [65]. Copyright 2019 The Royal Society of Chemistry.

2D Black phosphorus (BP) is another novel layered semiconductor with an allotrope of phosphorus, which has extraordinarily high charge mobilities of about $\sim 1000 \mathrm{~cm}^{2} \mathrm{~V}^{-1} \mathrm{~s}^{-1}[45,55,56]$. The bandgap of BP is adjustable from 0.3 to 1.8 , and $2.1 \mathrm{eV}$, corresponding to the bulk, bilayers, and monolayer, respectively, which enables BP to match well with the bandgap of the donor and acceptor in the OSCs.

In 2019, Chen et al. studied the application of the embedded BP nanoflakes in the active layer of OSCs [66]. They used the liquid-phase exfoliation method to fabricate $\mathrm{BP}$ nanoflakes with the size of $46 \mathrm{~nm}$ and re-dispersed them in chlorobenzene. The incorporation of BP nanoflakes can form the $\pi-\pi$ stacking ordering and optimize the phase purity of the active layer, contributing to the improved charge mobilities and suppressed charge recombination. As a result, the PCE of $12.2 \%$ can be obtained for the OSCs based on PTB7-Th:IEICO-4F with the Jsc of $23.94 \mathrm{~mA} \mathrm{~cm}^{-2}$, Voc of $0.72 \mathrm{~V}$, and FF of 0.73. Besides, the thermal stability of the device with BP nanoflakes was investigated by thermal treatment at $150{ }^{\circ} \mathrm{C}$, which remains $73 \%$ of the original PCE compared with the reference device of $60 \%$.

However, the traditional exfoliation method for the fabrication of BP may limit the application due to the poor dispersibility of BP clusters in organic solvents. Liu et al. exhibited a one-step solvothermal method to produce BP from the cheap and available white phosphorus and also incorporated them into the active layer of the OSCs [67]. Due to the noncovalent interactions between PTB7-Th and BP, the uniform and continuous active layer can be observed in the AFM image as shown in Figure 4a, additionally, the 2D GIWAXS patterns (see Figure $4 b, c$ ) displayed similar diffraction patterns in the active layer with or w/o BP incorporation, which illustrated the BP hardly affected the crystallization of donor and acceptor and the phase separation of the active layer. As indicated in Figure $4 \mathrm{~d}$, the PCE of $10.5 \%$ was realized in the device based on PTB7-Th:PC ${ }_{71} \mathrm{BM}$ incorporating with $10 \mathrm{wt} \% \mathrm{BP}$ in the active layer, resulting from the improvement of the carrier mobility and charge collection. 
Carrier mobility is one of the key factors to determine the device performance $A$ few $2 \mathrm{D}$ materials like bismuth oxychalcogenides $\left(\mathrm{Bi}_{2} \mathrm{O}_{2} \mathrm{X}\right)$ have a large surface area with excellent carrier mobility and high electron affinity, which can be applied in the photovoltaics $[68,69]$. Besides, the $\mathrm{Bi}_{2} \mathrm{O}_{2} \mathrm{X}$, such as $\mathrm{Bi}_{2} \mathrm{O}_{2} \mathrm{~S}, \mathrm{Bi}_{2} \mathrm{O}_{2} \mathrm{Se}$ and $\mathrm{Bi}_{2} \mathrm{O}_{2}$ Te have suitable bandgaps about $1.27 \mathrm{eV}, 0.8 \mathrm{eV}$ and $0.11 \mathrm{eV}$, respectively. In 2019 , Huang et al. reported the $2 \mathrm{D} \mathrm{Bi}_{2} \mathrm{O}_{2} \mathrm{~S}$ as a potential candidate for the performance improvement of the OSCs [70]. The $\mathrm{Bi}_{2} \mathrm{O}_{2} \mathrm{~S}$ nanomaterial synthesized by the hydrothermal method was incorporated into the PTB7:PC ${ }_{71} \mathrm{BM}-$ based binary OSCs. The results showed that the $\mathrm{Bi}_{2} \mathrm{O}_{2} \mathrm{~S}$ nanomaterial with a suitable energy band structure is matchable with the donor and acceptor materials, which can promote the exciton dissociation and charge transfer in the active layer. As a result, the PCE of the ternary OSCs by incorporating the $1 \mathrm{wt} \% \mathrm{Bi}_{2} \mathrm{O}_{2} \mathrm{~S}$ nanomaterial was improved from $8.79 \%$ to $10.71 \%$ compared with the binary OSCs.

Another $2 \mathrm{D} \mathrm{Bi} \mathrm{O}_{2}$ Se nanoflakes have high carrier mobility about $450 \mathrm{~cm}^{2} \mathrm{~V}^{-1} \mathrm{~s}^{-1}$ at room temperature with a tunable bandgap about $1.9 \mathrm{eV}$ in monolayer and $0.8 \mathrm{eV}$ in bulk [71-75]. In 2020, Huang et al. fabricated the $2 \mathrm{D} \mathrm{Bi}_{2} \mathrm{O}_{2}$ Se nanoflakes by liquid-phase exfoliation with lithium intercalation and incorporate them into the active layer of the OSCs as an additive [76]. It was suggested that the $2 \mathrm{D} \mathrm{Bi}_{2} \mathrm{O}_{2} \mathrm{Se}$ nanoflakes not only promoted the crystallization of the active layer and optimized the interpenetrating networks, but also increased the contact area between the donor and acceptor and provide efficient charge transfer pathways, improving the exciton separation and charge transfer in the active layer. The optimized ternary OSCs with the addition of $2 \mathrm{wt} \% \mathrm{Bi}_{2} \mathrm{O}_{2}$ Se nanoflakes presented the PCE of $16.28 \%$ based on PM6:Y6 blend active layer compared with the $14.59 \%$ of the binary device. Meanwhile, the devices incorporated with $2 \mathrm{D} \mathrm{Bi}_{2} \mathrm{O}_{2} \mathrm{Se}$ nanoflakes exhibited remarkable stability in the air for 30 days without any encapsulation. The OSCs within $2 \mathrm{wt} \% \mathrm{Bi}_{2} \mathrm{O}_{2}$ Se nanoflakes remained $91 \%$ of the original PCE, while the control devices only remained $77 \%$, which was mainly attributed to the better morphology stability and higher crystallization of the active layer with $\mathrm{Bi}_{2} \mathrm{O}_{2} \mathrm{Se}$ incorporation.

Mxene is another novel 2D material with outstanding optoelectronic performance, which consists of transition metal carbides, nitrides, or carbonitrides with a thickness of several atomic layers $[77,78]$. They have extra high conductivity due to the hydroxyl or terminal oxygen on the surface of MXene. Recently, Zhao et al. incorporated the solutionprocessed MXene material, titanium carbide $\left(\mathrm{Ti}_{3} \mathrm{C}_{2} \mathrm{~T}_{\mathrm{x}}\right)$ nanosheets into the active layer of OSCs as shown in Figure 4e, obtaining an improvement in the device performance [79]. The additive almost not affected the interpenetrating network morphology, and further provided an alternative way for the charge transport within the active layer. As revealed in Figure $4 \mathrm{f}$, the $\mathrm{Ti}_{3} \mathrm{C}_{2} \mathrm{~T}_{\mathrm{x}}$ nanosheets boosted the light-harvesting of the active layer, leading to the significant enhancement in $\mathrm{J}_{\mathrm{sc}}$ from $24.72 \mathrm{~mA} \mathrm{~cm}^{-2}$ to $27.02 \mathrm{~mA} \mathrm{~cm}^{-2}$ based on PM6:Y6-based OSCs. It was worth noting that the addition of $\mathrm{Ti}_{3} \mathrm{C}_{2} \mathrm{~T}_{\mathrm{x}}$ nanosheets improves the exciton dissociation, optimizes the charge transfer, and reduces the bimolecular recombination. The researchers found that the PCE of the OSCs based on PM6:Y6 increased from $14.64 \%$ to $16.25 \%$ by adding the optimum concentration of $0.05 \mathrm{wt}^{\circ} \mathrm{Ti}_{3} \mathrm{C}_{2} \mathrm{~T}_{\mathrm{x}}$ into the active layer, as exhibited in Figure $4 \mathrm{~g}, \mathrm{~h}$.

The main working mechanisms of the 2D materials as additives in the active layer of the OSCs we mentioned above can be concluded as follows: (1) Expand the light absorption range of the active layer; (2) modify the energy levels of heterojunctions for effectively improved the charge transfer; (3) act as conductive bridges or optimize the domain sizes in the heterojunction to increase charge transport. We partly summarized the applications of 2D materials as additives in the active layer for the enhancement of the device efficiency beyond $7 \%$ in Table 2 . The breakthroughs of the efficiency and stability of the OSCs could be expected by adding suitable $2 \mathrm{D}$ materials into active layer, as the solubility of more $2 \mathrm{D}$ materials can be improved. 
(a)

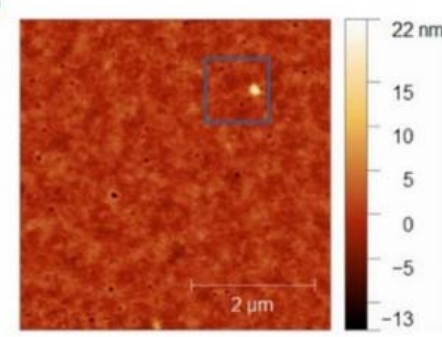

(d)

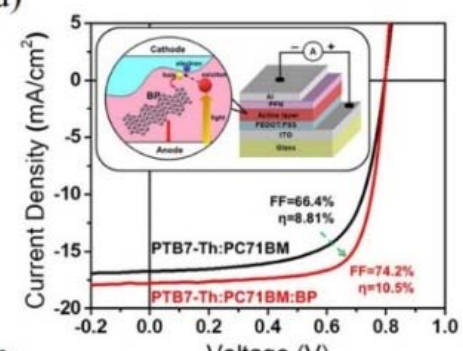

(f)

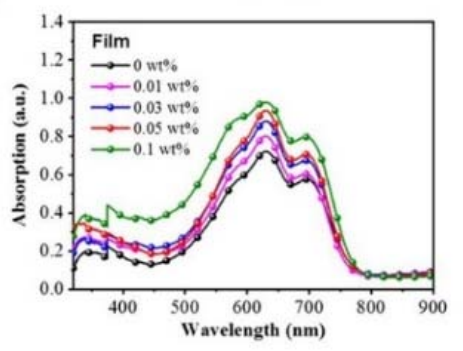

(b)

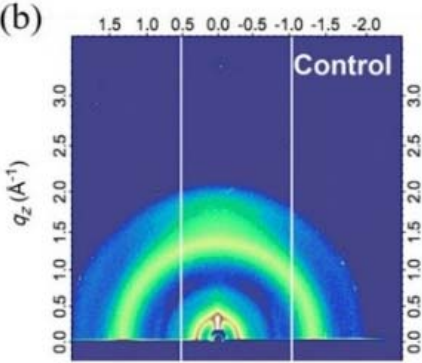

(e)

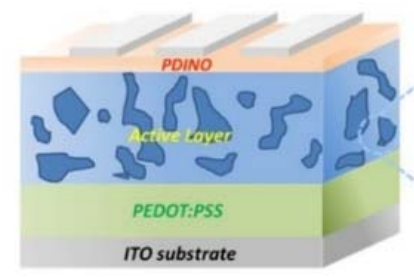

(g)

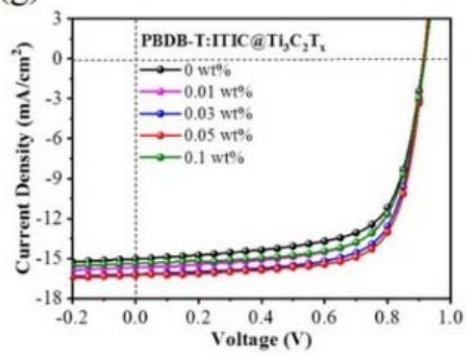

(c)

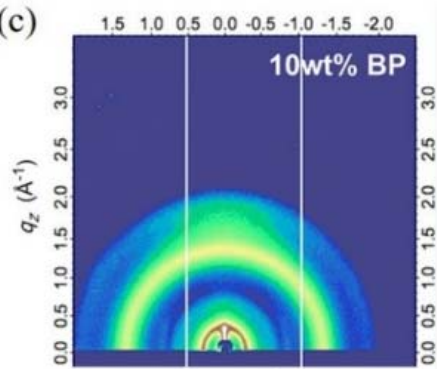

$q_{x y}\left(\mathrm{~A}^{-1}\right)$

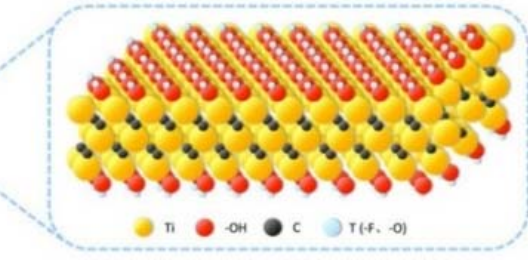

(h)

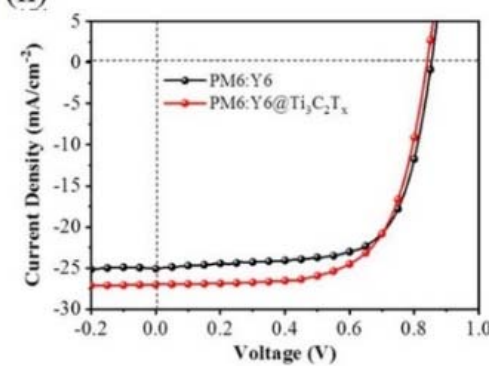

Figure 4. (a) AFM height images for PTB7-Th:PC 71 BM:BP blend film; 2D GIWAXS patterns of PTB7-Th:PC 71 BM:BP blend films with various concentration of BP: (b) $0 \mathrm{wt} \%$ and (c) $10 \mathrm{wt} \%$; (d) $\mathrm{J}-\mathrm{V}$ curves of a reference device and the best OSCs with the addition of BP. Inset: The structure of devices and the schematic diagram of light absorption, exciton migration, and separation; (e) The structure of OSCs and the schematic structure of $\mathrm{Ti}_{3} \mathrm{C}_{2} \mathrm{~T}_{\mathrm{x}}$; (f) UV-vis absorption spectra of PBDB-T:ITIC doped with different concentration of $\mathrm{Ti}_{3} \mathrm{C}_{2} \mathrm{~T}_{\mathrm{x}}$, and (g) the related J-V curves of the corresponding OSCs; (h) The optimal J-V curves of PM6:Y6@ $@ \mathrm{Ti}_{3} \mathrm{C}_{2} \mathrm{~T}_{\mathrm{x}}(0.05 \mathrm{wt} \%)$-based devices. Reprinted with permission form [67,79]. Copyright 2018 Elsevier Ltd. and 2021 John Wiley and Sons.

Table 2. 2D layer materials incorporated into the active layer of the OSC with PCE over 7\%.

\begin{tabular}{|c|c|c|c|c|c|c|c|c|c|c|}
\hline NO. & Materials & Function & Device Structure & $\begin{array}{c}\mathrm{Jsc} \\
\left(\mathrm{mA} / \mathrm{cm}^{2}\right)\end{array}$ & $\begin{array}{l}\text { Voc } \\
\text { (V) }\end{array}$ & FF (\%) & $\begin{array}{l}\text { PCE } \\
(\%)\end{array}$ & $\begin{array}{c}\text { PCE En- } \\
\text { hancement } \\
(\%)\end{array}$ & Year & Ref. \\
\hline 1 & TPP:GO & $\mathrm{AL}$ & ITO/PEDOT:PSS/PTB7:PC 71 BM:TPP:GO/ $\mathrm{MoO}_{3} / \mathrm{Au}$ & 18.27 & 0.78 & 63 & 8.81 & 19.21 & 2015 & [63] \\
\hline 2 & $\mathrm{WSe}_{2}$ & $\mathrm{AL}$ & Glass/ITO/PFN/PTB7:WSe $2: \mathrm{PCBM} / \mathrm{MoO}_{3} / \mathrm{Al}$ & 17.84 & 0.73 & 72 & 9.45 & 16.67 & 2017 & [64] \\
\hline 3 & $\mathrm{MoSe}_{2}$ & AL & ITO/ZnO/PBDTTBO:IT-4F:MoSe $2 / \mathrm{MoO}_{3} / \mathrm{Ag}$ & 19.37 & 0.73 & 56 & 7.92 & 8.13 & 2019 & [65] \\
\hline 4 & $\mathrm{MoSe}_{2}$ & $\mathrm{AL}$ & ITO/ZnO/PTB7-TH:PC 71 BM:MoSe $2 / \mathrm{MoO}_{3} / \mathrm{Ag}$ & 18.69 & 0.78 & 70 & 10.44 & 15.74 & 2019 & [65] \\
\hline 5 & $\mathrm{BP}$ & AL & $\begin{array}{l}\text { ITO/PEDOT:PSS/PTB7- } \\
\text { Th:PC }{ }_{71} \mathrm{BM}: \mathrm{BP} / \mathrm{PFN} / \mathrm{Al}\end{array}$ & 18.00 & 0.80 & 75 & 10.50 & 19.18 & 2018 & [67] \\
\hline 6 & $\mathrm{BP}$ & $\mathrm{AL}$ & ITO/ZnO/J71:ITIC:BP $/ \mathrm{MoO}_{3} / \mathrm{Al}$ & 16.6 & 0.95 & 60 & 9.41 & 11.89 & 2018 & [67] \\
\hline 7 & $\mathrm{BP}$ & $\mathrm{AL}$ & ITO/ZnO/PTB7-Th:IEICO-4F:BP/ $\mathrm{MoO}_{3} / \mathrm{Ag}$ & 23.44 & 0.71 & 70 & 12.2 & 12.96 & 2019 & [66] \\
\hline 8 & $\mathrm{Bi}_{2} \mathrm{O}_{2} \mathrm{~S}$ & AL & 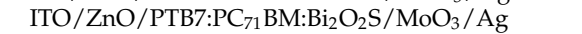 & 19.25 & 0.79 & 70 & 10.71 & 21.84 & 2019 & [70] \\
\hline 9 & $\mathrm{Bi}_{2} \mathrm{O}_{2} \mathrm{Se}$ & $\mathrm{AL}$ & ITO/ZnO/PBDB-T:ITIC: $\mathrm{Bi}_{2} \mathrm{O}_{2} \mathrm{Se} / \mathrm{MoO}_{3} / \mathrm{Ag}$ & 17.88 & 0.93 & 73 & 12.22 & 21.22 & 2020 & [76] \\
\hline 10 & $\mathrm{Bi}_{2} \mathrm{O}_{2} \mathrm{Se}$ & $\mathrm{AL}$ & ITO/ZnO/PM6:Y6: $\mathrm{Bi}_{2} \mathrm{O}_{2} \mathrm{Se} / \mathrm{MoO}_{3} / \mathrm{Ag}$ & 25.18 & 0.84 & 77 & 16.28 & 11.58 & 2020 & [76] \\
\hline 11 & $\mathrm{Ti}_{3} \mathrm{C}_{2} \mathrm{~T}_{\mathrm{x}}$ & $\mathrm{AL}$ & ITO/PEDOT:PSS/PM6:Y6: $\mathrm{Ti}_{3} \mathrm{C}_{2} \mathrm{~T}_{\mathrm{x}} / \mathrm{PDINO} / \mathrm{Al}$ & 27.02 & 0.840 & 72 & 16.25 & 10.99 & 2021 & [79] \\
\hline 12 & $\mathrm{Ti}_{3} \mathrm{C}_{2} \mathrm{~T}_{\mathrm{x}}$ & $\mathrm{AL}$ & $\begin{array}{c}\text { ITO/PEDOT:PSS/PBDB-T:IT- } \\
\text { M:Ti }{ }_{3} C_{2} \mathrm{~T}_{\mathrm{x}} / \mathrm{PDINO} / \mathrm{Al}\end{array}$ & 17.65 & 0.94 & 60 & 9.96 & 10.05 & 2021 & [79] \\
\hline 13 & $\mathrm{Ti}_{3} \mathrm{C}_{2} \mathrm{~T}_{\mathrm{x}}$ & $\mathrm{AL}$ & $\begin{array}{l}\text { ITO/PEDOT:PSS/PBDB- } \\
\text { T:ITIC:Ti }{ }_{3} C_{2} \mathrm{~T}_{\mathrm{x}} / \mathrm{PDINO} / \mathrm{Al}\end{array}$ & 16.28 & 0.92 & 72 & 10.72 & 14.8 & 2021 & [79] \\
\hline
\end{tabular}

\section{The Application of 2D Materials in the HTL}

Apart from as additives in the active layer of OSCs, the 2D materials can also be applied in the HTL of the devices. One of the widely studied 2D materials is TMDs, which have been applied to a series of organic photovoltaic owing to their fabulous photoelectric 
properties. Early in 2013, Sun et al. integrated the 2D MoS 2 nanosheets into the inverted OSCs as a HTL replacing the evaporated $\mathrm{MoO}_{3}$ [80]. The $\mathrm{MoS}_{2}$ nanosheets with layered structure could be easily obtained by chemical exfoliation and had good solubility in isopropyl alcohol. The devices based on P3HT:PC 61 BM and PTB7:PC ${ }_{71} \mathrm{BM}_{\text {with }} \mathrm{MoS}_{2}$ as HTL had achieved the highest PCE of $4.03 \%$ and $8.11 \%$, respectively. Similarly, Sun et al. incorporated the $\mathrm{NbSe}_{2}$ nanosheets as the $\mathrm{HTL}$ replacing the $\mathrm{MoO}_{3}$ into the inverted OSCs. A PCE of $8.10 \%$ had been achieved based on PTB7:PC 71 BM [81]. Both $\mathrm{MoS}_{2}$ and $\mathrm{NbSe}_{2}$ have unique 2D TMD structures, in which exhibits Van der Waals interaction among the thin layers with outdangling bonds, showing great chemical inertia with few trapping sites.

Later in 2018, Park et al. implemented WSe ${ }_{2}$ into PEDOT:PSS solution by forming a uniform dispersion and acting as the additive of HTL in the OSCs [82]. The surface of $\mathrm{WSe}_{2}$ films contained a negative charge, which weakened the Coulombic interaction between PEDOT and PSS, resulting in the phase separation of PEDOT:PSS, enhancing the conductivity of PEDOT:PSS and finally providing alternative pathways for the carrier transport. The incorporation of $\mathrm{WSe}_{2}$ into PEDOT:PSS led to the improvement of PCE from $7.3 \%$ to $8.5 \%$ in OSCs based on PTB7:PC 71 BM under the optimized conditions.

Currently, Anthopoulos et al. reported that the incorporation of liquid-exfoliated $\mathrm{WS}_{2}$ and $\mathrm{MoS}_{2}$ as the solution-processed HTL in the devices instead of PEDOT:PSS with the conventional structure exhibiting better device performances [83]. The conventional device structure was shown in Figure 5b. The deposition of $\mathrm{WS}_{2}$ increased the work function of ITO (Figure 5c) and formed more continuous films on the substrate, which could improve the charge extraction and transport, as well as suppress bimolecular recombination. As displayed in Figure 5d, the devices based on the ternary bulk-heterojunction structure of PBDBT-2F:Y6:PC 71 BM had obtained the highest PCE of $17 \%$, which was due to the enhanced $\mathrm{FF}$ of $78 \%$ and $\mathrm{Jsc}$ of $26 \mathrm{~mA} \mathrm{~cm}^{-2}$.

(a)

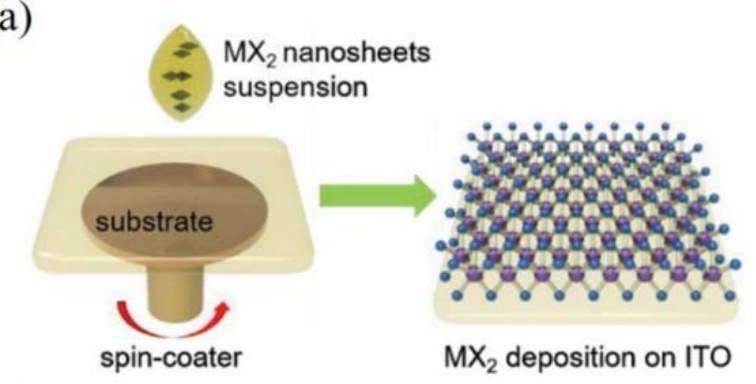

(c)

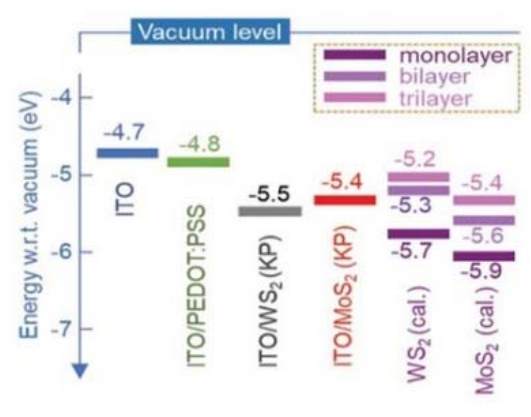

(b)

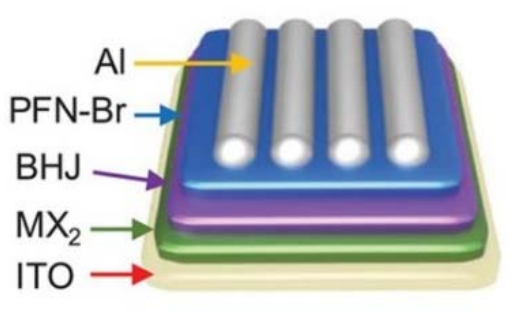

(d)

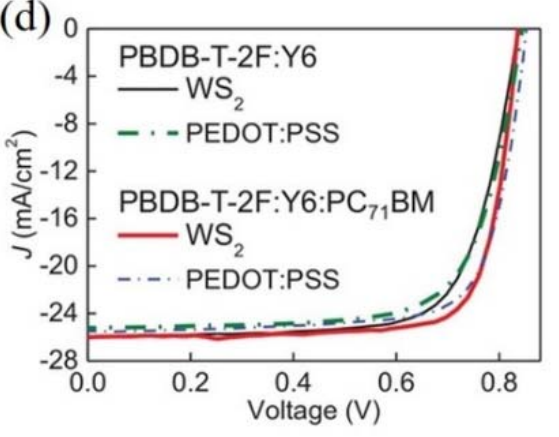

Figure 5. Schematic illustration of (a) the deposition of $\mathrm{MoS}_{2}$ and $\mathrm{WS}_{2}$ HTLs onto the substrate via spin-coating and (b) the device structure of OSCs; (c) The work function of ITO and HTLs deposited on ITO; (d) J-V curves of devices based on PBDB-T-2F:Y6 and PBDB-T-2F:Y6:PC 71 BM with PEDOT:PSS and $\mathrm{WS}_{2}$ as HTL, respectively. Reprinted with permission form [83]. Copyright 2019 Deerfield Beach.

Additionally, 2D metal oxide materials can also be competitors as HTL in OSCs. In 2015, Jang et al. used PEDOT:PSS and $\mathrm{WO}_{3}$ as HTL and fabricated tandem OSCs with the structure of Au-doped graphene nanoribbons/PEDOT:PSS+WO $3 / \mathrm{SMPV}_{2}: \mathrm{PC}_{71} \mathrm{BM} / \mathrm{ZnO} /$ PEDOT:PSS/PTTBDT-FTT:PC ${ }_{71} \mathrm{BM} / \mathrm{Ca} / \mathrm{Al}$ [84]. The incorporated $\mathrm{WO}_{3}$ improved the 
work function between the anode and active layer and decreased the surface roughness of the PEDOT:PSS with highly uniform film, which was beneficial to the hole transport. It is demonstrated that the device using both HTL materials showed better performance than that only using PEDOT:PSS or $\mathrm{WO}_{3}$ as HTL alone. Finally, the tandem device showed a PCE of $8.48 \%$ with Jsc of $8.45 \%$, Voc of $1.56 \mathrm{~V}$, and FF of $64.32 \%$. GO also has a strong interaction with PEDOT:PSS, and simultaneously the chemical modification methods can be used to enhance its photoelectric properties. In 2014, Song et al. demonstrated highly efficient OSCs by using PEDOT:PSS+GO composite films as HTLs [85]. The Raman spectroscopy characteristics indicated that the interaction of GO and PEDOT:PSS changed the conformation structure of PEDOT:PSS chains from a benzoid structure to a quinoid structure, improving the electric conductivity of PEDOT:PSS films, which enhanced the hole mobility and inhibited the exciton quenching and recombination. Thus, the devices based on PTB7:PC 71 BM had achieved an enhancing PCE from $7.04 \%$ to $8.21 \%$.

The reduced graphene oxide (rGO) functionalized by fluorine groups (F-rGO) can be also used as HTLs in OSCs. Chen et al. synthesized the F-rGO with enhanced conjugation of $\mathrm{C}=\mathrm{C}$ bonds, increasing the conductivity of HTL films [86]. The fluorine groups have high electronegativity, which can increase the WF of F-rGO from $5.1 \mathrm{eV}$ to $4.9 \mathrm{eV}$, optimizing the energy alignments and facilitating the hole transport in the devices. Consequently, the OSCs based on PTB7-Th:PC 71 BM with F-rGO as HTL had obtained the PCE of 8.6\%, which was higher than that of the devices with PEDOT:PSS HTL.

It is well known that the conductivity of GO nanosheets in the vertical direction can be easily affected by their thickness. In 2018, Choy et al. studied a novel quasi3D nanocomposite as a p-type top HTL to solve the influence of the thickness of GO nanosheets [87]. The author combined $\mathrm{NiO}_{\mathrm{x}}$ nanoparticles on the surface of $\mathrm{GO}$ nanosheets through hydrogen bond interaction in the ethanol solvent as shown in Figure 6a. The GO nanosheets with low and high level oxidation were both synthesized, and it was found that the former had superior dispersion than the latter in the mixture. As displayed in Figure $6 \mathrm{~b}$, the nanocomposite $\mathrm{HTL}$ with $\mathrm{NiO}_{x}$ had a smaller LUMO energy level at $1.55 \mathrm{eV}$, leading to better electron blocking ability compared with thin GO films. Due to the p-type semiconductor properties of $\mathrm{NiO}_{x}$ nanoparticles, the limitation of the vertical conductivity of GO was improved with approximately 15 times higher, which effectively suppressed the inefficient hole extraction at the interface of HTL and active layer (Figure 6c). With the incorporation of quasi-3D nanocomposites, the champion devices based on PBDB-T:IT-M had achieved the highest PCE of $12.13 \%$.

(a)

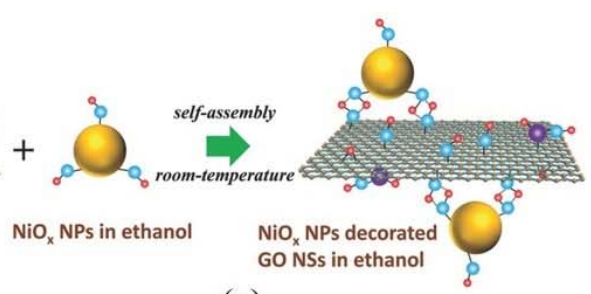

(c)

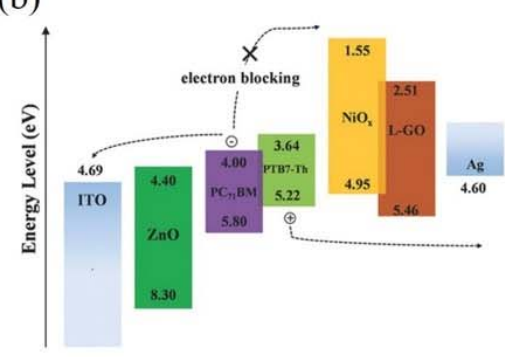

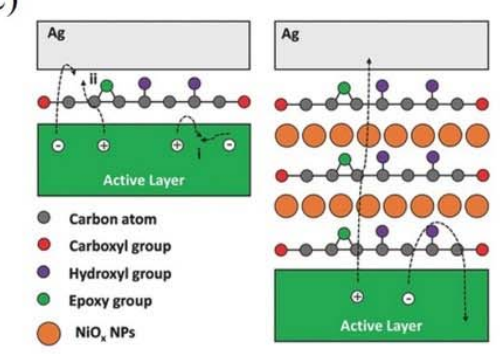
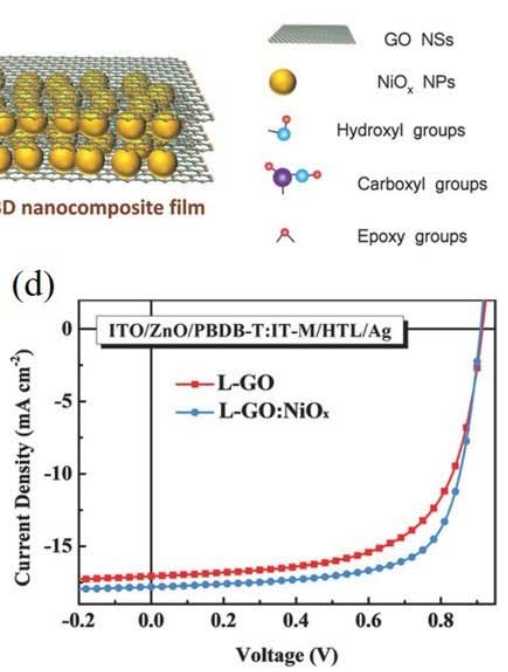

Figure 6. (a) Schematic diagram of preparing quasi-3D GO: $\mathrm{NiO}_{\mathrm{x}}$ nanocomposite; (b) Energy levels of materials in OSCs; (c) Schematic illustration of carrier extraction and interface dynamics; (d) J-V curves of devices based on PBDB-T:IT-M. Reprinted with permission form [87]. Copyright 2018 John Wiley and Sons. 
In addition, the hybrids of two types of 2D materials as HTL were successfully fabricated by Wang et al. [88]. The composition of $\mathrm{MoS}_{2}$ attached to 2D graphene (GMo) with three different amounts of 1:1,1:2, and 1:3 were employed as the HTL in the OSCs. The hybrid layer of GMo (1:3) exhibited stronger light absorption, indicating that more sunlight can be absorbed within the active layer. Besides, the dangling-oxygen bonds with strong electronegativity on the sulfur sites of $\mathrm{MoS}_{2}$ increased the p-type doping effect of the HTL owing to the electron consumption and hole accumulation. Thus, a high PCE of 9.5\% had achieved in OSCs based on PTB7-Th:PC ${ }_{71} \mathrm{BM}$.

Similarly to TMDs, $2 \mathrm{D} \alpha-\mathrm{In}_{2} \mathrm{Se}_{3}$, a compound semiconductor with elements of III-VI group, has greatly anisotropic electrical and optical properties. In 2020, Wang et al. utilized the liquid-phase exfoliation method to fabricate the $2 \mathrm{D} \alpha-\mathrm{In}_{2} \mathrm{Se}_{3}$ nanosheets as the HTL for the first time [89]. Benefiting from the smooth surface and the hydrophobicity properties, $\alpha-\mathrm{In}_{2} \mathrm{Se}_{3}$ nanosheets facilitated the hole transport in the devices. A high PCE of $9.58 \%$ was achieved based on the devices of ITO $/ \alpha-\mathrm{In}_{2} \mathrm{Se}_{3} / \mathrm{PBDB}-\mathrm{T}$ :ITIC $/ \mathrm{Ca} / \mathrm{Al}$, which is comparable to the control devices with PEDOT:PSS as HTL (9.5\%). Meanwhile, they incorporated the 2D $\alpha$ - $\mathrm{In}_{2} \mathrm{Se}_{3}$ nanosheets into PEDOT:PSS to enhance the conductivity of PEDOT:PSS in the devices as shown in Figure 7a [90]. The results illustrated that the interaction between the $\alpha-\mathrm{In}_{2} \mathrm{Se}_{3}$ nanosheets and solvent shields the Coulombic effect between PEDOT and PSS, which led to the benzoid-quinoid transition of PEDOT chains and enlarged the conductive amounts of PEDOT chains (Figure 7b). Therefore, the PCE of PM6:Y6-based devices with the composite HTL (2D $\alpha-\operatorname{In}_{2} \mathrm{Se}_{3}+$ PEDOT:PSS) was improved from $14.50 \%$ to $15.89 \%$ as seen in Figure 7c.

(a)

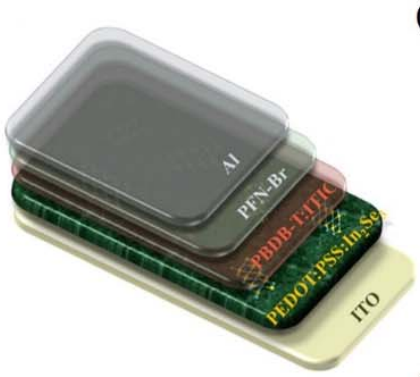

(d)

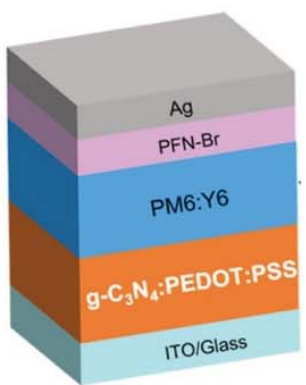

(b)

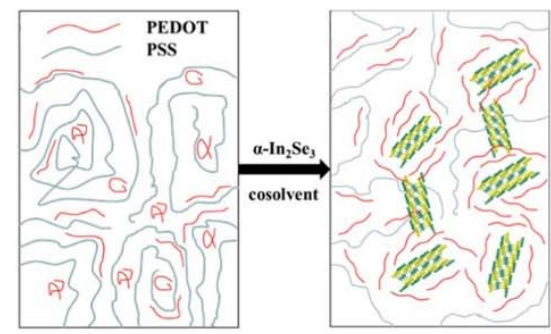

(e)

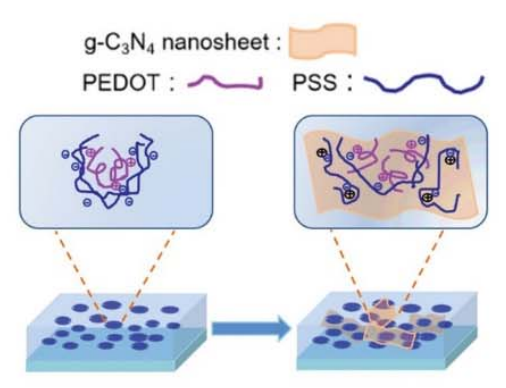

(c)

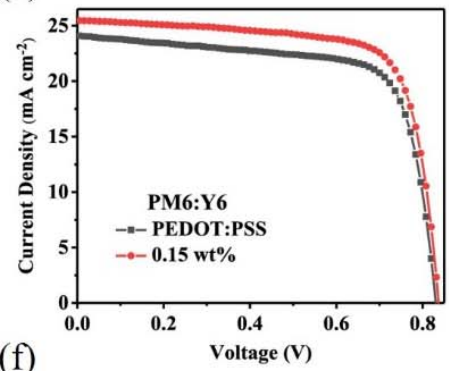

(f)

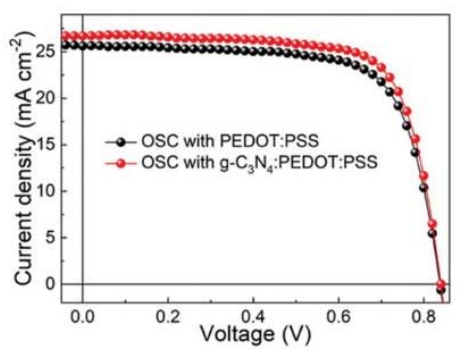

Figure 7. Schematic diagram of (a) the device architecture and (b) the mechanism of the conductivity enhancement; (c) J-V curves of the control devices and the devices with the addition of $0.15 \mathrm{wt} \% \alpha-\mathrm{In}_{2} \mathrm{Se}_{3}$. Reprinted with permission form [90]. Copyright 2020 American Chemical Society. Schematic diagram of (d) the device structure and (e) compositional changes of PEDOT:PSS before and after the doping of $\mathrm{g}-\mathrm{C}_{3} \mathrm{~N}_{4}$; (f) J-V curves of OSCs with $\mathrm{g}-\mathrm{C}_{3} \mathrm{~N}_{4}$ :PEDOT:PSS as HTL. Reprinted with permission form [27]. Copyright 2020 John Wiley and Sons.

$2 \mathrm{D} \mathrm{g}-\mathrm{C}_{3} \mathrm{~N}_{4}$ with stable chemical properties and excellent photoelectric behaviors have drawn much attention. In 2020, Liu et al. incorporated $2 \mathrm{D}$ g- $\mathrm{C}_{3} \mathrm{~N}_{4}$ into the PEDOT:PSS as the HTL in OSCs (Figure 7d) [27]. The g- $\mathrm{C}_{3} \mathrm{~N}_{4}$ could be protonated to carry positive charges, attracting the insulating and hydrophilic PSS chains and weakening the interaction between PEDOT and PSS, as shown in Figure 7e. Therefore, more conductive PEDOT chains were released from the core-shell structures, which can substantially improve 
the conductivity of PEDOT:PSS, increase the carrier transport and further suppress the bimolecular recombination at the interface between HTL and the active layer. As displayed in Figure $7 \mathrm{f}$, after adding $2 \mathrm{D}$ g- $\mathrm{C}_{3} \mathrm{~N}_{4}$ into the PEDOT:PSS, the PCE of the OSCs with the structure of ITO/g- $\mathrm{C}_{3} \mathrm{~N}_{4}+\mathrm{PEDOT}: \mathrm{PSS} / \mathrm{PM} 6: \mathrm{Y} 6 / \mathrm{MoO}_{3} / \mathrm{Au}$ had been boosted from $15.29 \%$ to $16.38 \%$, owing to the improved Jsc and FF.

Numerous 2D materials have tunable energy levels and high hole mobility. The application of the novel 2D materials in the HTL can optimize the charge transport process in the devices, which is an effective way to enhance the performance of the devices. In Table 3, the performances of 2D nanomaterials applied as HTL in the OSCs and the relevant device photovoltaic parameters are summarized. The application of stable 2D materials in the HTL with high conductivity and carrier mobility, not only to enhance the PCE of the devices, but also to improve the stability of the OSCs should be got more attention in the further research.

Table 3. 2D layer materials incorporated into HTL.

\begin{tabular}{|c|c|c|c|c|c|c|c|c|c|c|}
\hline NO. & Materials & Function & Device Structure & $\begin{array}{c}\mathrm{Jsc} \\
\left(\mathrm{mA} / \mathrm{cm}^{2}\right)\end{array}$ & $\begin{array}{l}\text { Voc } \\
\text { (V) }\end{array}$ & FF (\%) & $\begin{array}{l}\text { PCE } \\
(\%)\end{array}$ & $\begin{array}{c}\text { PCE En- } \\
\text { hancement } \\
(\%)\end{array}$ & Year & Ref. \\
\hline 1 & $\mathrm{MoS}_{2}$ & HTL & $\mathrm{ITO} / \mathrm{ZnO} / \mathrm{PTB} 7: \mathrm{PC}_{71} \mathrm{BM} / \mathrm{MoS}_{2} / \mathrm{Ag}$ & 15.90 & 0.72 & 71 & 8.11 & 7.56 & 2013 & [80] \\
\hline 2 & $\mathrm{NbSe}_{2}$ & HTL & ITO/ZnO/PTB7:PC 71 BM/NbSe $/$ Ag & 16.04 & 0.72 & 70 & 8.10 & 7.42 & 2014 & [81] \\
\hline 3 & $\mathrm{WSe}_{2}$ & HTL & ITO/PEDOT:PSS+WSe 2 /PTB7:PC 71 BM/Al & 16.60 & 0.78 & 66 & 8.5 & 19.71 & 2018 & {$[82]$} \\
\hline 4 & $\mathrm{WS}_{2}$ & HTL & $\begin{array}{l}\text { ITO/WS } / \text { PBDB-T-2F:Y6:PC }{ }_{71} \mathrm{BM} / \mathrm{PFN}-\mathrm{Br} / \mathrm{Al} \\
\text { Glass / Au-doped single layer graphene }\end{array}$ & 26.00 & 0.84 & 78 & 17.00 & 6.25 & 2019 & [83] \\
\hline 5 & $\mathrm{WO}_{3}$ & HTL & $\begin{array}{c}\text { nanoribbons /PEDOT:PSS+WO } \mathrm{WO}_{3} / \mathrm{SMPV1} \mathrm{PC}_{71} \mathrm{BM} / \\
\text { ZnO/PEDOT:PSS/PTTBDT- } \\
\text { FTT:PC } \\
\text { BM } / \mathrm{Ca} / \mathrm{Al}\end{array}$ & 8.45 & 1.56 & 64 & 8.48 & 34.81 & 2015 & [84] \\
\hline 6 & GO & HTL & ITO/PEDOT:PSS+GO/PTB7:PC 71 BM/Al & 16.42 & 0.76 & 65 & 8.21 & 16.61 & 2014 & [85] \\
\hline 7 & F-rGO & HTL & ITO/F-rGO/PTB7-Th:PC ${ }_{71} \mathrm{BM} / \mathrm{PFN} / \mathrm{Al}$ & 16.89 & 0.78 & 65 & 8.60 & 8.86 & 2017 & [86] \\
\hline 8 & $\begin{array}{l}\mathrm{L}-\mathrm{GO} \\
+\mathrm{NiO}_{x}\end{array}$ & HTL & ITO/ZnO/PBDB-T:IT-M/L-GO+NiO $/$ Ag & 18.07 & 0.92 & 73 & 12.13 & 21.17 & 2018 & [87] \\
\hline 9 & $\mathrm{GO}+\mathrm{MoS}_{2}$ & HTL & ITO/GO+MoS 2 /PEDOT:PSS/P3HT:PC 71 BM/Ca/Ag & 17.20 & 0.77 & 72 & 9.50 & 5.5 & 2019 & [88] \\
\hline 10 & $\alpha-\operatorname{In}_{2} \mathrm{Se}_{3}$ & HTL & $\mathrm{ITO} / \alpha-\mathrm{In}_{2} \mathrm{Se}_{3} / \mathrm{PBDB}-\mathrm{T}: \mathrm{ITIC} / \mathrm{Ca} / \mathrm{Al}$ & 16.69 & 0.88 & 65 & 9.58 & 0.8385 & 2019 & [89] \\
\hline 11 & $\alpha-\operatorname{In}_{2} \mathrm{Se}_{3}$ & HTL & $\begin{array}{c}\text { ITO/PEDOT:PSS }+\alpha- \\
\mathrm{In}_{2} \mathrm{Se}_{3} / \mathrm{PM} 6: \mathrm{Y} 6 / \mathrm{PDINO} / \mathrm{Al}\end{array}$ & 15.47 & 0.84 & 74 & 15.90 & 9.89 & 2020 & [90] \\
\hline 12 & $\mathrm{~g}-\mathrm{C}_{3} \mathrm{~N}_{4}$ & HTL & ITO/PEDOT:PSS+g- $\mathrm{C}_{3} \mathrm{~N}_{4}$ & 26.71 & 0.84 & 73 & 16.38 & 7.13 & 2020 & [27] \\
\hline
\end{tabular}

\section{The Application of 2D Materials in the ETL}

In OSCs, a conventional structure with PEDOT:PSS as HTL and low work function electrode usually confronted with long-term instability. Therefore, an inverted device structure with a high work function metal electrode that could improve the stability of the device has been widely adopted. Zinc oxide ( $\mathrm{ZnO})$, due to its high transmittance, tunable electronic features, and good stability, is one of the widely used ETL in the inverted OSCs [91]. Nevertheless, there are also a few structural drawbacks of ZnO that limit its further application in fabricating high-efficient inverted OSCs, especially the surface defects of $\mathrm{ZnO}$ will generate recombination centers to trap electrons because of the presence of $\mathrm{Zn}$ /oxygen vacancies, which impedes the local charge transfer of the devices [92].Recently, to overcome the intrinsic drawbacks of $\mathrm{ZnO}$, lots of researches have shown that $2 \mathrm{D}$ layered materials with high optoelectronic performance have the potentiality as additives in ETL of OSCs, owing to their tunable work function and high electron mobility, which can help to lower the work function of the cathode and facilitate the electron transfer of the OSCs [48].

It has been firstly reported by Lin, et al. in 2016 that BP can be served as an effective ETL in OSCs [93]. They spin-coated solution exfoliated BP flakes onto the ZnO ETL layer to change the electron transport behavior in OSCs, showing a positive effect on the performance of inverted devices. Figure $8 \mathrm{a}, \mathrm{b}$ show that the morphologies of drop-casted BP flakes in TEM images. The top inset of Figure $8 b$ is the energy dispersive X-ray (EDX) spectrum of the sample, and the bottom inset is the selected area electron diffraction (SAED) pattern indicating the high crystalline quality of the synthesized BP. Figure $8 \mathrm{~d}$ is the architecture of the inverted OSC with the addition of BP in the ETL. As shown in the $\mathrm{J}-\mathrm{V}$ and EQE characteristics in Figure 8e,f, the average PCE of the optimal device based on $\mathrm{ZnO} / \mathrm{BP} / \mathrm{PTB} 7: \mathrm{PC}_{71} \mathrm{BM}$ was improved from $7.37 \%$ to $8.18 \%$ with $11 \%$ higher than that of 
the control device. The $\mathrm{V}_{\mathrm{OC}}$ and FF had no distinct differences, while the improvement of the device efficiency was mainly contributed to the increase of JSC. The incorporation of BP as ETL resulted in a cascaded band structure (seen in Figure 8c), which effectively promoted the electron transport and prohibited the carrier recombination between the ETL and the active layer.
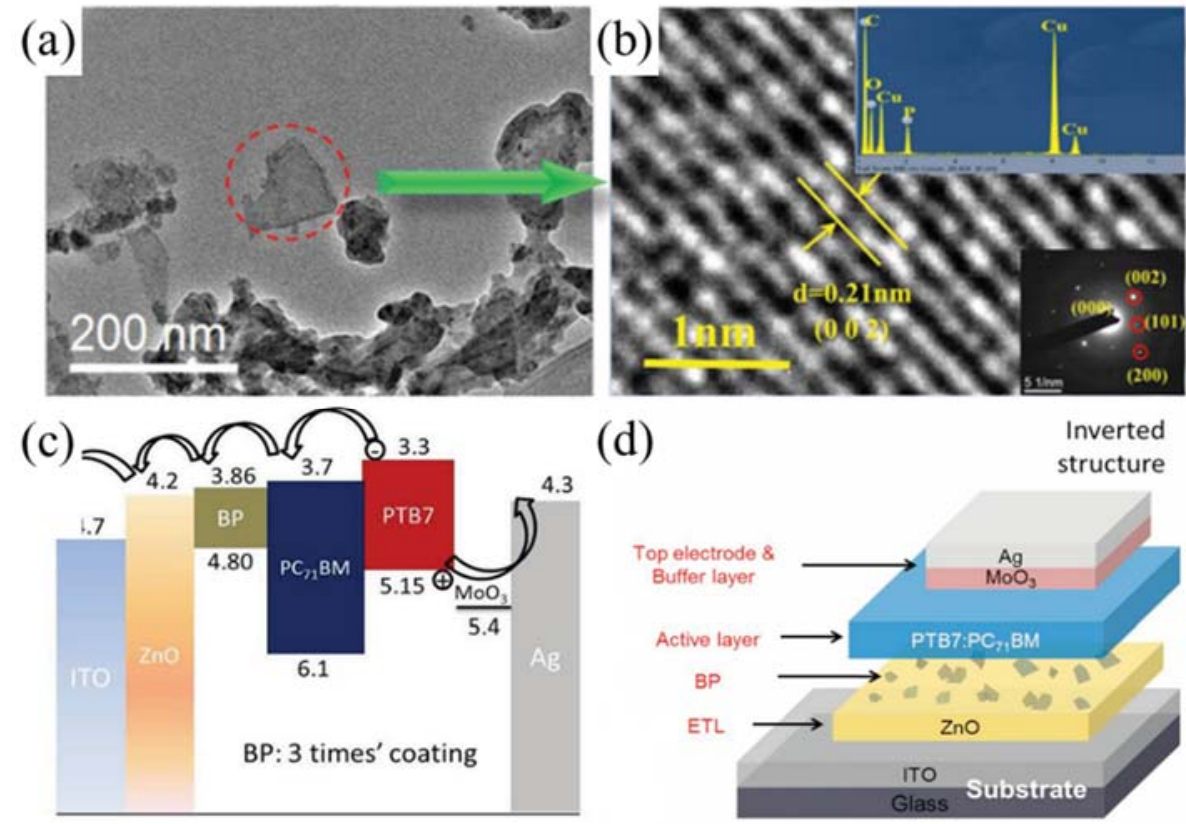

(d)

Inverted
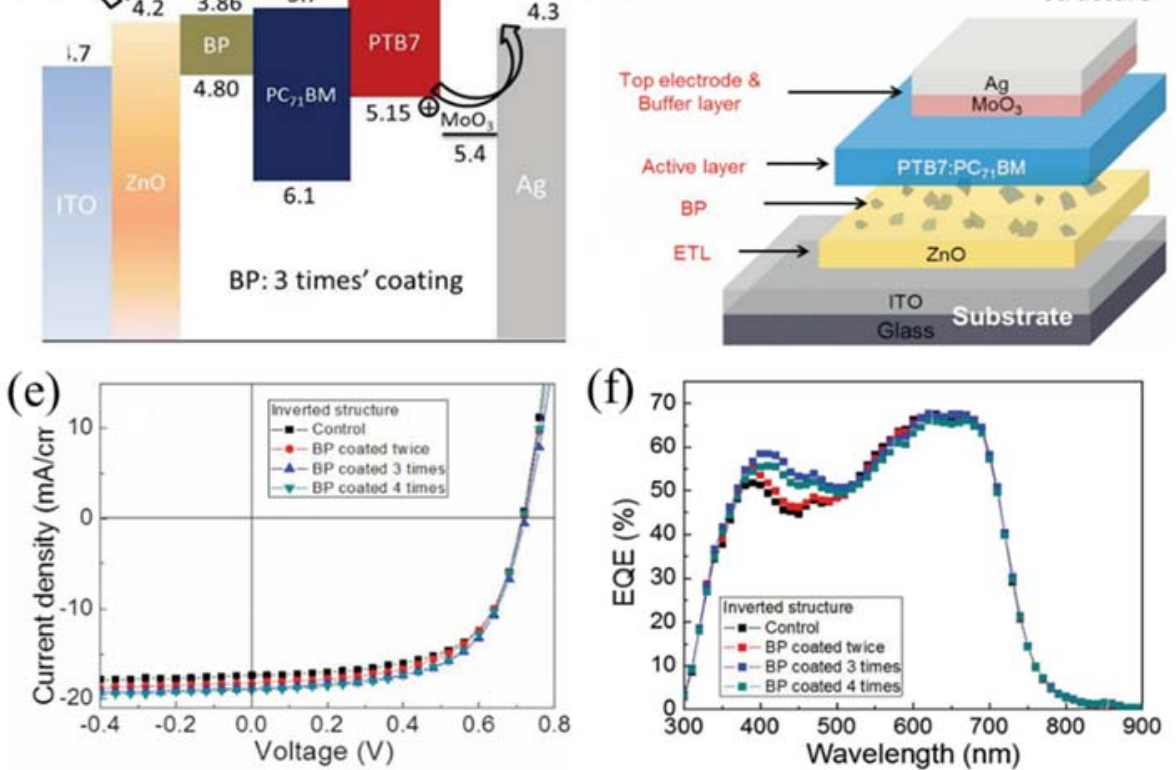

Figure 8. (a) TEM image of drop-casted BP flakes; (b) HRTEM image of the BP flake, the insets are SAED pattern (top) and EDX result (bottom); (c) Energy band structure of the OSCs with the incorporation of BP; (d) Inverted architectures of OSCs based on PTB7/PC 71 BM.; (e) J-V characteristics of inverted OSCs; (f) EQE characteristics of a control device and the inverted OSCs. Reprinted with permission form [93]. Copyright 2016 John Wiley and Sons.

Graphene oxide (GO) and its derivatives were also employed to improve the performance of ETL, owing to their solution-processability and tunable work function characteristics. Konios, et al. studied the PTB7:PC 71 BM-based OPVs utilized GO-Cl as HTL and GO-Li as ETL [94]. The structure of the devices and their related J-V characteristics were shown in Figure $9 \mathrm{~b}$. The incorporation of GO-Cl as HTL and GO-Li as ETL significantly increased the device efficiency by around $12 \%$ and $8 \%$, compared to the control device with PEDOT:PSS as $\mathrm{HTL}$ and $\mathrm{TiO}_{X}$ as ETL, respectively. The enhancement was not only attributed to the effect of WF tunability to form a cascaded energy level with GO addition (Figure 9a), but also the smooth and low resistance interface created by the unique 2D nature of GO, as well as the significant conductivity improvement of GO-Li-incorporated ETL. 
(a)
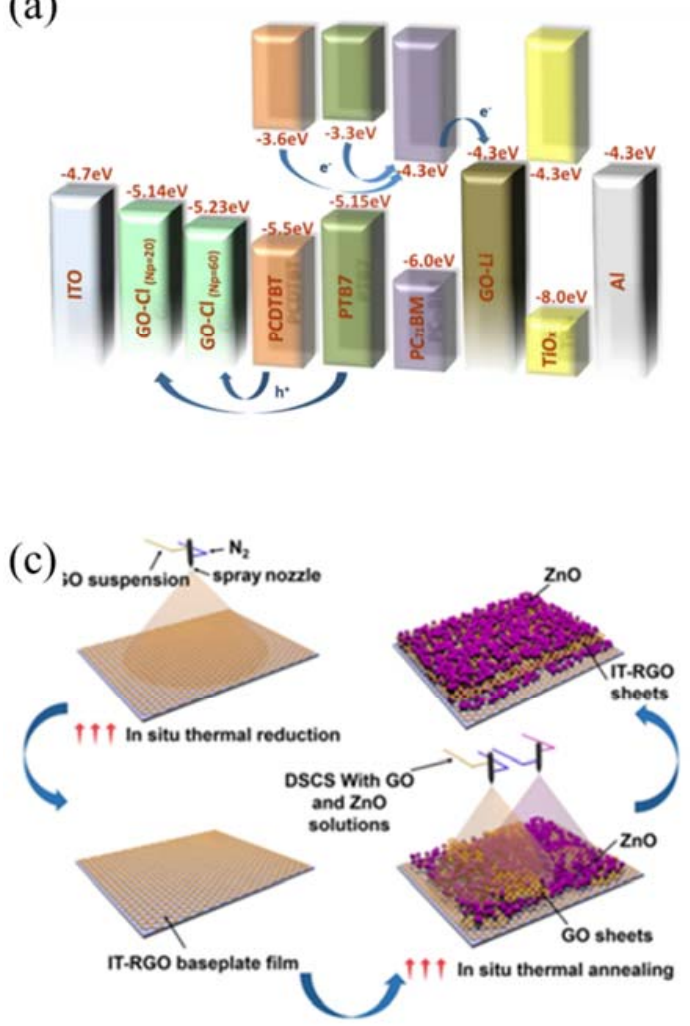
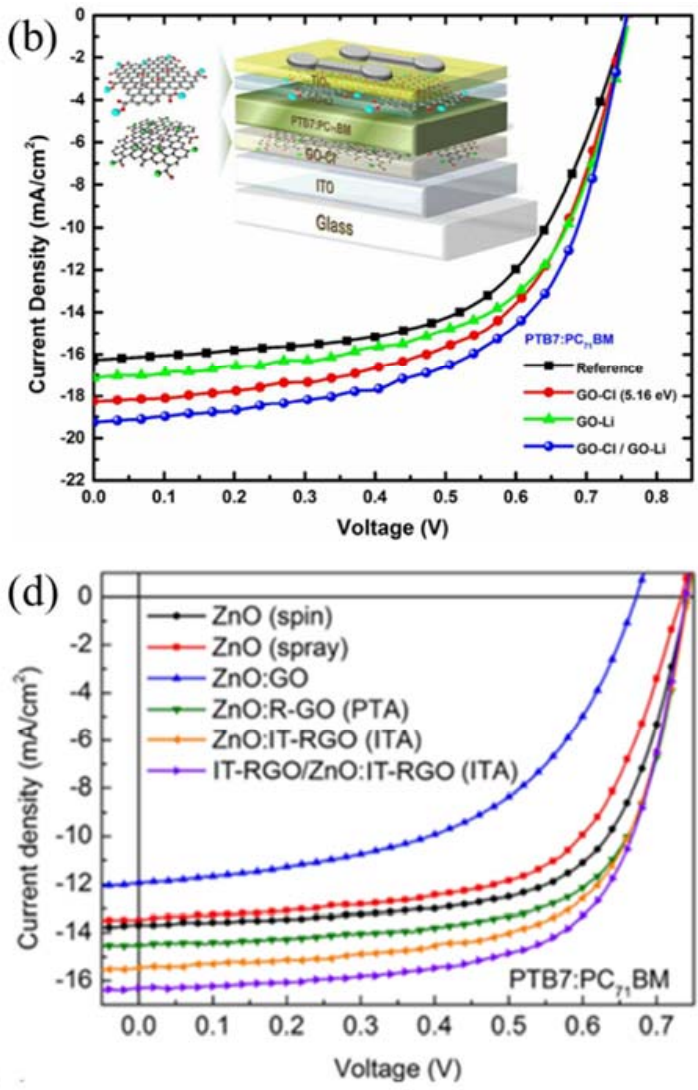

Figure 9. (a) Energy band structure of the OSCs with the incorporation of GO-Cl and GO-Li; (b) the architectures of OPVs based on PTB7:PC 71 BM and the J-V characteristics of the device; (c) the fabrication process of ZnO:IT-RGO hybrid ETL; (d) the J-V characteristics of OSCs based on different hybrid ETLs. Reprinted with permission form [94,95]. Copyright 2016 The Royal Society of Chemistry and 2017 American Chemical Society.

Compared to GO, the reduced graphene oxide (R-GO) with better conductivity and electron mobility, possesses lower WF which is more matchable with the LUMO of PC ${ }_{71} \mathrm{BM}$. However, the complicated reduction methods are incompatible with the low-temperature fabrication of OSCs, which become the limitation for the application of ZnO:R-GO hybrid ETL. In 2017, Zheng, et al. introduced an innovative method to precisely control the components of ZnO:IT-RGO hybrid ETL and realized the reduction of GO into IT-RGO within $15 \mathrm{~s}$ by utilizing an easy one-step in situ thermal reduction/annealing (ITR/ITA) method, as depicted in Figure 9c [95]. Compared to GO and R-GO, IT-RGO exhibited the highest conductivity, which lead to a better conductivity of the hybrid ZnO:IT-RGO than the bare $\mathrm{ZnO}$. Subsequently, the PTB7:PC 71 BM-based OSCs with bare $\mathrm{ZnO}, \mathrm{ZnO}: G O$, $\mathrm{ZnO}: \mathrm{R}-\mathrm{GO}$, and $\mathrm{ZnO}: \mathrm{IT}-\mathrm{RGO}$ as ETLs were fabricated, respectively to illuminate the effect of the different incorporation. The results in Figure $9 \mathrm{~d}$ showed that the device based on ZnO:IT-RGO hybrid ETL exhibited the highest PCE of 7.56\%, which is a $7.56 \%$ enhancement in comparison with the device based on ZnO:R-GO. Moreover, adding a thin IT-RGO film between ITO and ZnO:IT-RGO could remarkably enhance the PCE of the device with an optimal PCE of $9.49 \%$, resulting from the intrinsic high conductivity of IT-RGO and the homogeneous surface generated by ITA treatment, which facilitated the charge collection and inhibited the charge recombination in OSCs.

Furthermore, N-doped GR shows better performance than both GO and R-GO. In 2019, Li, et al. added N-doped GR into PDINO to prepare a solution-processable material (PDINO-G) as ETL in OSCs [96]. They utilized PDINO as the dispersant for GR and the source of nitrogen dopant. The effect of N-doped GR accelerated the charge transfer and enhanced the carrier extraction efficiency. As a result, the PTQ10:IDIC-2F-based OSCs with 
PDINO-G as ETL and PEDOT:PSS-GO as HTL exhibited the optimal PCE of $13.01 \%$, which performed much better than that of the device with bare PDINO (12.23\%).

With the rapid development of 2D materials, many emerging nanomaterials with excellent photoelectric properties have been synthesized and achieved extraordinary performance of the device when they were applied as ETL. 2D metal organic framework nanosheets (MOFs) possess unique optoelectronic behaviors, which can be applied to improve the optoelectronic property of $\mathrm{ZnO}$. However, the exfoliation of metal organic framework nanosheets with good dispersibility remains a challenge. In 2018, Xing, et al. addressed an efficient technique for exfoliating a novel tellurophene-based 2D metal organic framework to few-layer nanosheets with a branched polymer surfactant polyethylenimine ethoxylate (PEIE) [97]. The solution of MOF-PEIE nanosheets could be directly spin-cast onto the $\mathrm{ZnO}$ layer as additives without subsequent treatment in the inverted OSCs. As a result, the MOF-PEIE incorporated OSCs based on P3HT:PC ${ }_{61} \mathrm{BM}$ showed a PCE of $3.42 \%$ (Figure 10b), which was more than $25 \%$ enhancement in comparison with the control device. The enhancement was attributed to the simultaneous increase in $\mathrm{JSC}_{S \mathrm{C}}, \mathrm{V}_{\mathrm{OC}}$, and FF. Meanwhile, PBDB-T:ITIC-Th-based non-fullerene OSCs were also studied, which exhibited a similar enhanced result with the introduction of MOF-PEIE. It is demonstrated that the incorporation of MOF nanosheets into PEIE is beneficial to the passivation of the defects in $\mathrm{ZnO}$, which remarkably suppresses the carrier recombinations. Additionally, the MOFPEIE nanosheets can optimize the band structure of the device and improve the electrical conductivity of the $\mathrm{ZnO}$ layer.
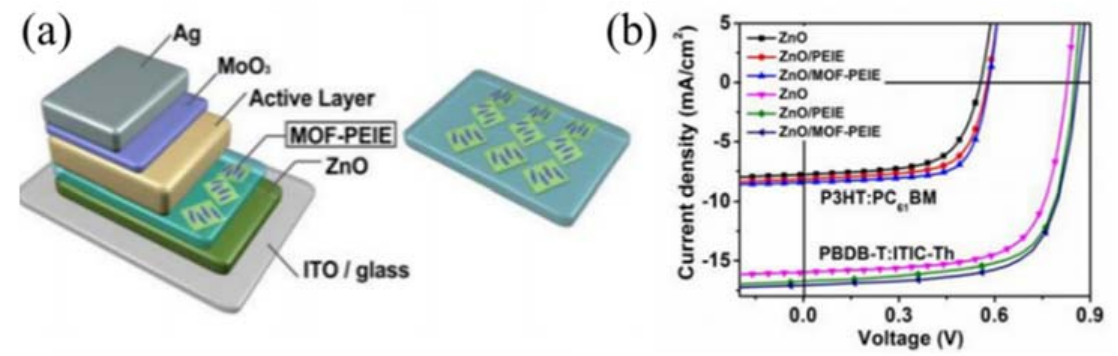

(c)

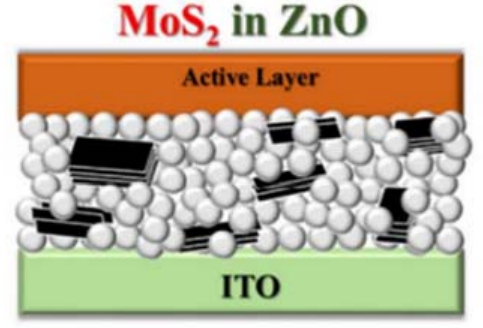

(e)

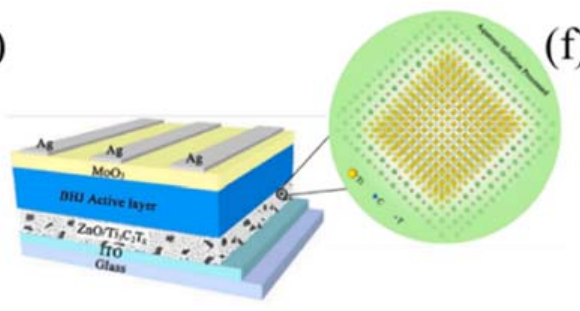

(d)

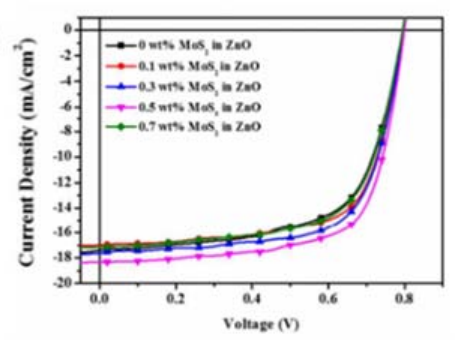

(f)

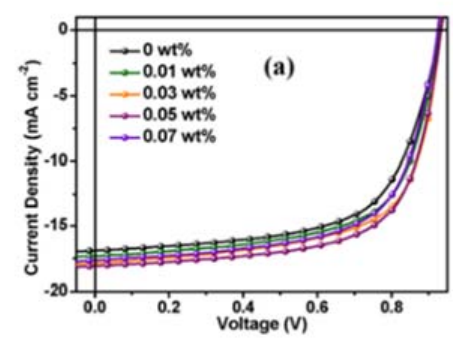

Figure 10. (a) The architectures of OPVs with ZnO ETL containing MOF-PEIE, and (b) the corresponding J-V characteristics based on P3HT:PC 61 BM and PBDB-T:ITIC-Th (c) the structure of $\mathrm{MoS}_{2}$ in $\mathrm{ZnO}$ ETL, and (d) the corrensponding J-V characteristics based on PTB7-TH:PC ${ }_{71} \mathrm{BM}$ with $\mathrm{ZnO}$ ETL in different incorporation of $\mathrm{MoS}_{2}(\mathbf{e})$ the structure of OSCs based on PBDB-T:ITIC with $\mathrm{Ti}_{3} \mathrm{C}_{2} \mathrm{~T}_{X}$, and (f) the corresponding J-V characteristics based on PBDB-T:ITIC with $\mathrm{Ti}_{3} \mathrm{C}_{2} \mathrm{~T}_{\mathrm{X}}$. Reprinted with permission form [91,97,98]. Copyright 2018 Elsevier Ltd., 2018 American Chemical Society and 2021 Elsevier Ltd. 
The versatile TMD nanosheets can be also introduced into the $\mathrm{ZnO}$ layer as ETL to fabricate the inverted OSCs for tuning the work function of $\mathrm{ZnO} . \mathrm{MoS}_{2}$ is a typical 2D TMDs material, which has been extensively studied in OSCs as HTL. Moreover, solutionprocessed $\mathrm{MoS}_{2}$ nanosheets possess lower trap densities and surface dipoles, which also provide an appropriate electrical field for charge transport and high charge mobility as an ETL material. Huang, et al. incorporated different $\mathrm{MoS}_{2}$ nanosheets into $\mathrm{ZnO}$ and achieved high performance of OSCs [91]. The champion device based on PTB7-TH:PC 71 BM with the incorporation of $0.5 \mathrm{wt} \% \mathrm{MoS}_{2}$, exhibiting Voc of $0.8 \mathrm{~V}$, Jsc of $18.4 \mathrm{~mA} \cdot \mathrm{cm}^{-2}$, an FF of $68.9 \%$, and a PCE of $10.1 \%$ (seen in Figure $10 \mathrm{~d}$ ), which is $15 \%$ enhancement in comparison to the PCE of the control device. The incorporation of $\mathrm{MoS}_{2}$ nanosheets not only aligned the energy band, optimized the interfacial smoothness, but also improved the electron transport in the ETL of the OSCs.

Currently, MXene, as a novel 2D transition metal carbide and nitride has high carrier mobility, unique optical transmittance, and charge carrier density, has attracted extensive attention in the optoelectronic field. Specifically, $\mathrm{Ti}_{3} \mathrm{C}_{2} \mathrm{~T}_{\mathrm{X}}$ is one of the most outstanding materials in MXene and has been applied in OSCs. Hou, et al. employed $\mathrm{Ti}_{3} \mathrm{C}_{2} \mathrm{~T}_{\mathrm{X}}$ as an additive to fabricate nanohybrid ETLs and investigated their micromorphology, photoelectricity properties [98]. They precisely adjusted the amount of $\mathrm{Ti}_{3} \mathrm{C}_{2} \mathrm{~T}_{\mathrm{X}}$ in sol-gel $\mathrm{ZnO}$ to investigate their potential applications as ETL based on fullerene (PTB7:PC $\left.{ }_{71} B M\right)$ and non-fullerene (PBDB-T:ITIC and PM6:Y6) systems. The results showed that the PBDB-T:ITIC-based OSCs with $\mathrm{ZnO} / \mathrm{Ti}_{3} \mathrm{C}_{2} \mathrm{~T}_{\mathrm{X}}$ ETL obtained a PCE of $12.20 \%$ (Figure 10f), revealing a $15.53 \%$ enhancement in comparison with the control device. In addition, the PM6:Y6-based devices with the same ETL material achieved an outstanding PCE enhancement from $14.99 \%$ to $16.51 \%$. It was suggested that the $\mathrm{Ti}_{3} \mathrm{C}_{2} \mathrm{~T}_{\mathrm{X}}$ nanosheets with high mobility and charge carrier density constructed additional charge transfer paths among the $\mathrm{ZnO}$ nanocrystals, which facilitated the charge transfer via forming a $3 \mathrm{D}$ interconnected structure in $\mathrm{ZnO} / \mathrm{Ti}_{3} \mathrm{C}_{2} \mathrm{~T}_{\mathrm{X}}$ ETL. Meanwhile, the $\mathrm{Ti}_{3} \mathrm{C}_{2} \mathrm{~T}_{\mathrm{X}}$ nanosheets passivated the surface of $\mathrm{ZnO}$ by generating $\mathrm{Zn}-\mathrm{O}-\mathrm{Ti}$ bonding, which may prolong the lifetime of the excitons in the OSCs.

It is worth noting that the $2 \mathrm{D}$ materials with excellent electrical property and high transmittance could be successfully applied to improve the charge transport between the active layer and ETL of the OSCs, optimize the interfacial smoothness, and align the energy levels of the devices. The incorporation of suitable 2D materials in the ETL usually could enhance the PCE of the OSCs over $10 \%$, which demonstrated that it is an efficient way to promote the performance of OSCs. The 2D materials employed as ETL materials mentioned above are listed with detailed information in Table 4 . We can notice that the 2D materials as ETL in the OSCs currently are almost incorporated into the $\mathrm{ZnO}$ layer as additives to improve the properties of the $\mathrm{ZnO}$, which limited the application of the 2D materials as ETL. It is expecting that the fabrication of large area 2D materials with uniform morphology can directly used as ETL instead of $\mathrm{ZnO}$ in the further research.

Table 4. 2D layer materials applied in the ETL of OSCs.

\begin{tabular}{|c|c|c|c|c|c|c|c|c|c|c|}
\hline NO. & Materials & Function & Device Structure & $\begin{array}{c}\mathrm{Jsc} \\
\left(\mathrm{mA} / \mathrm{cm}^{2}\right)\end{array}$ & $\begin{array}{l}\text { Voc } \\
\text { (V) }\end{array}$ & FF (\%) & $\begin{array}{l}\text { PCE } \\
(\%)\end{array}$ & $\begin{array}{c}\text { PCE En- } \\
\text { hancement } \\
(\%)\end{array}$ & Year & Ref. \\
\hline 1 & $\mathrm{BP}$ & ETL & $\mathrm{ITO} / \mathrm{ZnO}+\mathrm{BP} / \mathrm{PTB} 7: \mathrm{PC}_{71} \mathrm{BM} / \mathrm{MoO}_{3} / \mathrm{Ag}$ & 18.78 & 0.72 & 61 & 8.25 & 11.9 & 2016 & [93] \\
\hline 2 & GO & ETL & ITO/GO-Cl/PTB7:PC ${ }_{71} \mathrm{BM} / \mathrm{GO}-\mathrm{Li} / \mathrm{TiO}_{\mathrm{x}} / \mathrm{Al}$ & 19.59 & 0.78 & 61 & 9.14 & 23.68 & 2016 & [94] \\
\hline 3 & rGO & ETL & $\begin{array}{c}\text { ITO/IT-rGO/ZnO+IT-rGO/PTB7- } \\
\text { Th: } \mathrm{PC}_{71} \mathrm{BM} / \mathrm{MoO}_{3} / \mathrm{Ag}\end{array}$ & 18.61 & 0.78 & 65 & 9.49 & 20.35 & 2017 & [95] \\
\hline 4 & rGO & ETL & $\begin{array}{c}\text { ITO/IT-rGO/ZnO+IT- } \\
\text { rGO/PTB7:PC }{ }_{71} \mathrm{BM} / \mathrm{MoO}_{3} / \mathrm{Ag}\end{array}$ & 16.32 & 0.74 & 67 & 8.04 & 13.92 & 2017 & [95] \\
\hline 5 & Graphene & ETL & ITO/ZnO+PDINO-G/PM6:Y6/ $\mathrm{MoO}_{3} / \mathrm{Ag}$ & 25.12 & 0.82 & 76 & 15.70 & 15.6 & 2019 & [96] \\
\hline 6 & MOF-PEIE & ETL & $\begin{array}{c}\text { ITO/ZnO+MOF-PEIE/PBDB-T:ITIC- } \\
\text { Th/ } / \mathrm{MoO}_{3} / \mathrm{Ag}\end{array}$ & 17.09 & 0.86 & 71 & 10.39 & 14.80 & 2018 & [97] \\
\hline 7 & $\mathrm{MoS}_{2}$ & ETL & $\mathrm{ITO} / \mathrm{ZnO}+\mathrm{MoS}_{2} / \mathrm{PTB} 7-\mathrm{Th}: \mathrm{PC}_{71} \mathrm{BM} / \mathrm{MoO}_{3} / \mathrm{Ag}$ & 18.40 & 0.80 & 69 & 10.10 & 14.77 & 2018 & [91] \\
\hline 8 & $\mathrm{Ti}_{3} \mathrm{C}_{2} \mathrm{Tx}$ & ETL & ITO/ZnO+ $\mathrm{Ti}_{3} \mathrm{C}_{2} \mathrm{TX} / \mathrm{PBDB}-\mathrm{T}: \mathrm{ITIC} / \mathrm{MoO}_{3} / \mathrm{Ag}$ & 18.63 & 0.93 & 70 & 12.20 & 15.53 & 2020 & [98] \\
\hline 9 & $\mathrm{Ti}_{3} \mathrm{C}_{2} \mathrm{Tx}$ & ETL & $\mathrm{ITO} / \mathrm{ZnO}+\mathrm{Ti}_{3} \mathrm{C}_{2} \mathrm{~T}_{\mathrm{X}} / \mathrm{PM} 6: \mathrm{Y} 6 / \mathrm{MoO}_{3} / \mathrm{Ag}$ & 26.38 & 0.83 & 75 & 16.51 & 10.13 & 2020 & [98] \\
\hline
\end{tabular}




\section{The Application of 2D Materials in the Electrodes}

ITO as a traditional transparent electrode is frequently used as the bottom electrode in the OSCs. However, its brittleness and high cost have limited their future applications in flexible photovoltaics. More importantly, indium tends to spread through numerous layers into the photoactive layers of OSCs, which worsens the performance of the devices. Consequently, it's necessary to search for alternative transparent electrodes to substitute for ITO. Herein, 2D materials could be utilized as an electrode in OSCs owing to their high conductivity and high transmittance. In Table 5, we collected a series of 2D materials as the electrodes in the OSCs.

Table 5. 2D layer materials applied as the electrode in OSCs.

\begin{tabular}{|c|c|c|c|c|c|c|c|c|c|c|}
\hline NO. & Materials & Function & Device Structure & $\begin{array}{c}\mathrm{Jsc} \\
\left(\mathrm{mA} / \mathrm{cm}^{2}\right)\end{array}$ & $\begin{array}{l}\text { Voc } \\
\text { (V) }\end{array}$ & $\begin{array}{l}\mathrm{FF} \\
(\%)\end{array}$ & $\begin{array}{l}\text { PCE } \\
(\%)\end{array}$ & $\begin{array}{c}\text { PCE En- } \\
\text { hancement } \\
(\%)\end{array}$ & Year & Ref. \\
\hline 1 & Graphene & Anode & $\begin{array}{l}\text { Graphene/PEDOT:PSS/WO } \mathrm{W}_{3} / \mathrm{SMPV1}: \mathrm{PC}_{71} \mathrm{BM} / \\
\mathrm{ZnO} / \mathrm{PEDOT}: \mathrm{PSS} / \mathrm{PTTBDT}-\mathrm{FTT}: \mathrm{PC} 71 \mathrm{BM} / \mathrm{Ca} / \mathrm{Al}\end{array}$ & 8.45 & 1.56 & 64 & 8.48 & $/ 4.95$ & 2012 & {$[84]$} \\
\hline 2 & rGO & Anode & $\begin{array}{c}\text { rGO/PEDOT:PSS/PSEHTT:IC }{ }_{60} \mathrm{BA} / \mathrm{ZnO} / \\
\text { PEDOT:PSS/PBDTT-DPP:PC } \\
71 \text { BM/ } / \mathrm{TiO}_{2} / \mathrm{Ag} \text { NW }\end{array}$ & 7.62 & 1.62 & 64 & 8.02 & / & 2014 & [99] \\
\hline 3 & GO@AgNWs & Anode & GO@AgNW/PEDOT:PSS/PTB7:PC70BM/LiF:Al & 19.84 & 0.68 & 57 & 7.66 & 5.36 & 2017 & [100] \\
\hline 4 & EG & Anode & EG/PEDOT:PSS/PTB7:PC ${ }_{71 \mathrm{~B}} \mathrm{M} / \mathrm{Ba} / \mathrm{Al}$ & 9.97 & 0.72 & 59.3 & 4.23 & $/ 40.1$ & 2017 & [101] \\
\hline 5 & AgNWs-EG & Anode & AgNWs-EG/PEDOT:PSS/PTB7:PC 71 BM/Ba/Al & 15.5 & 0.73 & 58.3 & 6.57 & $/ 7.1$ & 2018 & [102] \\
\hline 6 & $\mathrm{GR} / \mathrm{ZnO}-\mathrm{NP}$ & Cathode & GR/ZnO-NP/PTB7-Th:PC ${ }_{71} \mathrm{BM} / \mathrm{MoO} 3 / \mathrm{Ag}$ & 16.26 & 0.76 & 66.4 & 8.16 & $/ 10.7$ & 2018 & [103] \\
\hline 7 & PI@GR & Anode & PI@GR/PEDOT:PSS/PM6:Y6/PDINO/Al & 25.8 & 0.84 & 70.2 & 15.2 & $/ 3.2$ & 2020 & [104] \\
\hline 8 & $\begin{array}{l}\text { MXene/AgNW- } \\
\text { PUA }\end{array}$ & Anode & $\begin{array}{l}\text { MXene/AgNW-PUA/PBDB- } \\
\text { T:ITIC:PC } 71 \text { BM/PDINO/AI }\end{array}$ & 14.85 & 0.88 & 63 & 8.30 & $/ 9.7$ & 2019 & [105] \\
\hline
\end{tabular}

A semitransparent tandem cell is popular among researchers for its high transparency and various applications such as building-integrated photovoltaic and solar-powered planes. Although the PCE of the devices with 2D material electrodes is still lower than the ITO-based devices, the 2D nanomaterials have promising properties especially their flexibility and cost-effectiveness, which overcomes the brittleness of ITO. In 2012, Yusoff et al. used $\mathrm{Au}$-doped single layer graphene nanoribbons (Au-doped SLGNRs) as a replacement for ITO [84]. The corporation of Au-doped SLGNRs enhanced the performance of the OSC due to the structure that enables hole transport from the active layer into the Au-doped SLGNRs anode. With the Au-doped SLGNRs implemented in tandem architecture, a PCE of $8.48 \%$ was reached, which was the highest PCE of ITO-free tandem OSC then. Later in 2014, the researcher used solution-processed graphene mesh as the transparent anode of the OSCs [99]. The structure and proposed energy-level diagram of the semitransparent tandem solar cell is shown in Figure 11a,b. The work functions of the materials are well-matched, which facilitates the charge carrier transport in the devices. The device performance of tandem graphene mesh cells was comparable to the tandem solar cells fabricated using ITO. An average PCE of $8.02 \%$ was obtained with a Voc of $1.62 \mathrm{~V}$, a Jsc of $7.62 \mathrm{~mA} \mathrm{~cm}^{-2}$, and a FF of $64.21 \%$ (Figure 11c).

Occasionally, the blend of two distinct materials could bring unexpected excellent effects. It's well-known that silver nanowire (AgNW) is an appropriate electrode material. Incorporating 2D material into AgNW could exhibit better performance. In 2017, Wang et al. integrated an AgNW mesh layer with graphene oxide (GO) in the OSC as a transparent conductive electrode. The device structure is shown in Figure 11d [100]. An OSC with $87 \%$ transmittance, sheet resistance value of $18 \Omega^{-1}$, remarkable long-term stability, and mechanical stability was exhibited by using the $\mathrm{GO} / \mathrm{AgNW}$ electrodes. Besides, as shown in (Figure 11e), a better light scattering than ITO electrodes was obtained with GO/AgNW electrodes on account of a photon trapping effect. As a result, after GO/AgNW electrodes were applied in the OSCs, the highest PCE of $7.66 \%$ was obtained in the PTB7:PC ${ }_{70} \mathrm{BM}-$ based system with a relative increase of $5.36 \%$ compared with the ITO electrode-based device (Figure 11f). 
(a)
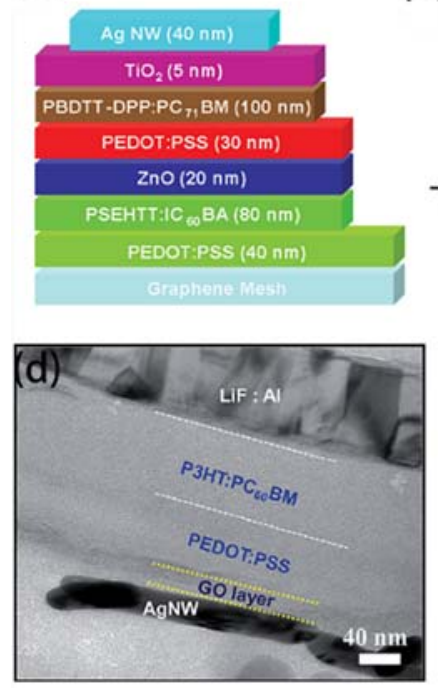

(b)

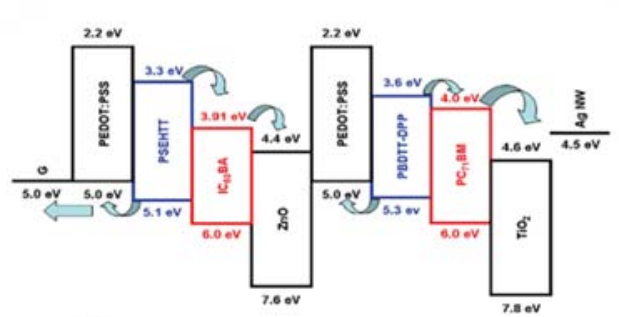

(e)

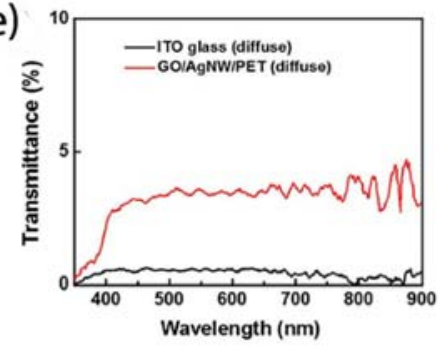

(c)

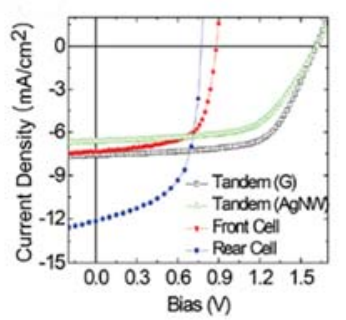

(f)

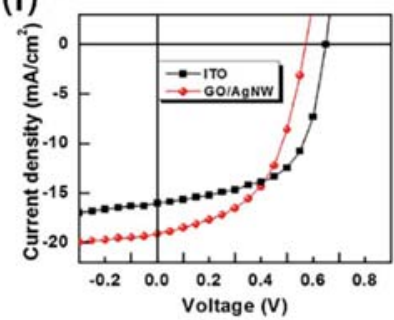

Figure 11. (a) The structure of semitransparent tandem cell with graphene mesh anode; (b) Proposed energy-level diagram of the semitransparent tandem cell with graphene mesh anode; (c) J-V curves of the front, rear, and tandem cells; (d) crosssectional HRTEM image of P3HT:PCBM-based OSCs with GO/AgNW; (e) Magnified diffuse transmittance spectra of ITO and GO/AgNW films; (f) J-V characteristics of PTB7:PC 70 BM OSCs with the GO/AgNW mesh electrode and the reference device with the ITO electrode. Reprinted with permission form [99,100]. Copyright 2017 The Royal Society of Chemistry and 2014 John Wiley and Sons.

Furthermore, the exfoliated graphene (EG) could also show remarkable performance as a transparent conductive electrode in OSCs for its excellent electronic and optical properties. In 2017, Ricciardulli et al. utilized solution-processed high-quality graphene as a transparent conductive electrode in OSCs. The best PCE of $4.23 \%$ was obtained in the PTB7:PC 71 BM-based OSCs [101]. Ricciardulli et al. reported the hybrids of AgNW and EG electrodes, then integrated them into the OSCs as an anode [102]. Although metal NW is an excellent substitute for ITO with its electrical and optical properties, it also has some disadvantages like high surface roughness and contact resistance. The RMS of AgNW falls from 16.4 to $4.6 \mathrm{~nm}$ after the incorporation of EG into the NW, which attributes to the flattening effect of EG. Ultimately, the PTB7:PC 71 BM-based OSCs with AgNWs-EG anode showed a Jsc of $15.5 \mathrm{~mA} \mathrm{~cm}^{-2}$, a Voc of $727 \mathrm{mV}$, and an FF of $58.3 \%$, giving a higher PCE of $6.57 \%$.

To avoid the defects caused by the annealing process, Jung et al. used an anneal-free process to fabricate the inverted OSCs with n-doped graphene electrodes using zinc oxide nanoparticles (ZnO-NP) in 2018 [103]. ZnO-NPs are excellent materials for charge transport at low-temperature for their outstanding charge mobility and transparency without further annealing treatment. GR/ZnO-NP hybrid materials were produced by coordinating the $\mathrm{ZnO}-\mathrm{NP}$ onto the lyophobic surface of GR. Eventually, the devices with GR/ZnO-NP electrodes reached a PCE of $8.16 \%$ on the solid substrates, which was comparable with the ITO electrodes. Similarly, in 2020, Koo et al. reported a flexible GR electrode with the integration of polyimide (PI), which has remarkable thermal stability. The devices were fabricated using PM6 and Y6 as the doner and accepter [104]. The chemical structures and band structure of the OSCs are shown in Figure 12a,b. PI is a flexible substrate for the GR electrode as well as a carrier film for GR. Through the assistance of the PI substrate, an ultraclean surface, an optical transmittance of $92 \%$, excellent thermal stability, and low sheet resistance were obtained. Besides, the durability of the electrode is also improved because the addition of PI restrains the delamination of GR under mechanical stress. Consequently, an OSC with a Jsc of $25.8 \mathrm{~mA} \mathrm{~cm}^{-2}$, a Voc of $0.84 \mathrm{~V}$, an FF of $70 \%$, and the highest PCE of $15.2 \%$ was successfully fabricated, which was close to the ITO-based reference device, as shown in Figure 12c. 
(a)

(d)
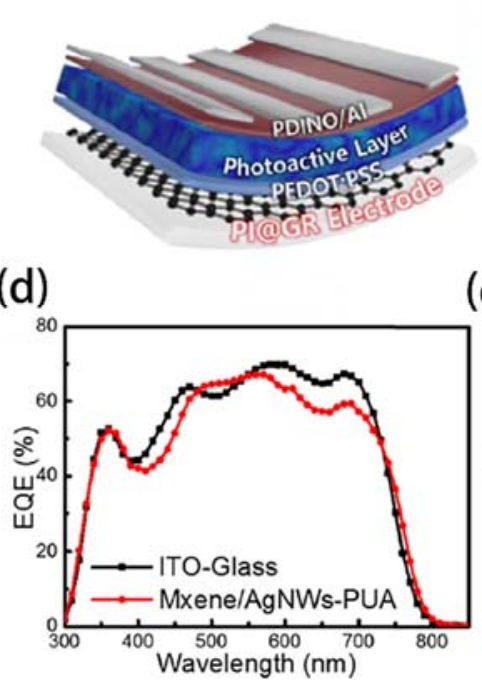

(b)

(e)

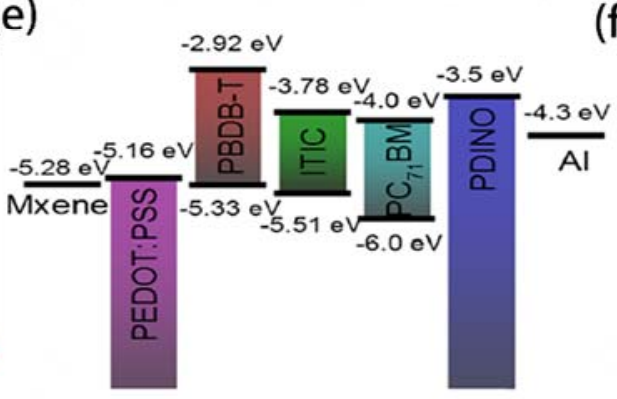

(c)

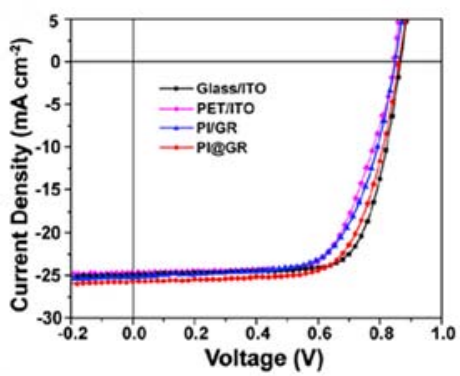

(f)

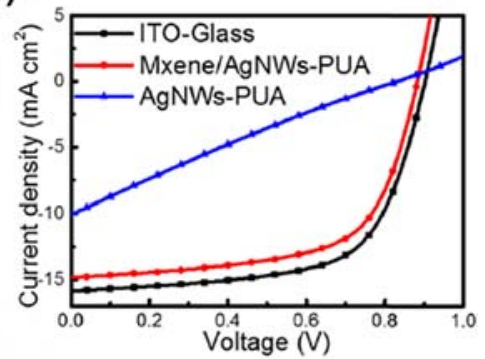

Figure 12. (a) Schematic of the device structure with PI@GR electrode; (b) The corresponding energy level diagram of the device; (c) J-V characteristics of PI@GR OSCs compared with OSCs with ITO; (d) EQE of OSCs based on PBDBT:ITIC:PC 71 BM with MXene/AgNW hybrid electrode; (e) Energy-level diagrams of OSCs based on PBDBT:ITIC:PC 71 BM; (f) J-V curves of the OSCs with MXene/AgNW hybrid electrode. Reprinted with permission form [104,105]. Copyright 2019 American Chemical Society and 2020 Elsevier Ltd.

Mxene, which has the fine property of hydrophilicity and metallic conductivity, could also serve as an additive for electrodes. Tang et al. applied MXene/AgNW flexible transparent conductive (FTCE) electrode into the flexible OSCs for the first time [105]. To deal with the roughness surface caused by the stacking of hybrid materials, the AgNW network was partially inserted into the surface of a poly(urethane acrylate) (PUA) matrix. Besides, the MXene coating was processed through electrostatic interactions. The MXene/AgNW hybrid films showed remarkable electrical conductivity, well-matched work function levels (seen in Figure 12e), low roughness, robust mechanical performance, and high transmittance. From Figure 12d, we can find higher EQE values at $550 \mathrm{~nm}$ compared to the ITO-based electrode, which further demonstrates the performance improvement of the hybrid electrode based on Mxene/AgNWs. A high PCE of 8.30\% was achieved by the device with MXene/AgNW-based hybrid FTCE and a ternary structure of PBDB-T:ITIC:PC ${ }_{71} \mathrm{BM}$ as a photoactive layer, as displayed in Figure 12f.

\section{Conclusions}

In this review, we summarized the application of the novel 2D layered materials in different positions of the OSCs, which exhibited a positive and remarkable enhancement effect on the photovoltaic performance of the devices. Incorporating the 2D materials into the active layer, they mainly act as the third component to expand the light absorption range of the active layer, modify the energy levels and enhance the charge transport of the devices. While the 2D materials processed high hole or electron mobilities could be favorable for optimizing the charge transport characteristics of the CTL, which can be applied into the HTL or ETL of the OSCs. On one hand, they may replace the role of the original HTL/ETL materials for improving the stability of the OSCs. On the other hand, the 2D materials can be also introduced into the CTL as additives for boosting the PCE and stability of the devices. Additionally, the 2D materials, such as GR and its derivatives, which meet the requirements of the bottom electrode of OSCs with relatively high transparency, stability, and excellent conductivity can be also employed as electrode replacements in the OSCs. Moreover, most of the 2D materials can be solution synthesized and conveniently integrated into the fabrication process of the OSCs. It provides them 
to modify the interface between the electrode and active layer, and also optimize the morphologies of the CTL and active layer.

How to select the function of the 2D materials? Generally, the large area 2D materials with intact and uniform morphology, which process excellent conductivity, high transparency, and matable energy levels with the CTL can be used as the electrodes of the OSCs. Particularly for the flexible and semitransparent OSC devices, the suitable 2D materials, such as graphene, GO, etc. have been widely used as the electrodes of the devices. In addition, 2D materials for the application in the active layer of the OSCs uaually have high carrier mobility, broad light absorption wavelength, and tunable bandgaps. Most importantly, they should firstly meet the requirement that the materials need have good solubility in the organic solvent, which can guarantee the 2D additives blended uniformly with the active layer materials. For the application in the HTL or ETL, 2D materials usually have p-type or n-type semiconductor properties for the facilitation of hole or electron transportation, respectively. High carrier mobilities and matable energy levels between the active layer and electrodes are also important for selection of the 2D materials used in the CTL.

Although the 2D layered materials show great potential in the application of OSCs, there still remain several big challenges. The layer-dependent optical and electronic properties of the 2D materials and the difficulty to control their morphology in the devices are the major obstacles for the application in the OSCs. In addition, the expensive cost with a relatively low yield of the 2D materials also limited their further applications. At present, the instability of some specific 2D materials, such as BP, and their low solubility in organic solvent significantly impede their incorporation in OSCs, especially in the active layer. However, nowadays, the strategies on the stability improvement and large-scale fabrication of the 2D materials are increasingly putting forwarded. For example, the recent double encapsulation technique make the OSCs with integration of 2D materials can be stroed in the air for a long period [106]. The research on the controllable solvent-process to fabricate the novel 2D layered materials will make the large-scale production with high yield of the materials a reality in the near future. It is foreseeable that with the developments of the novel 2D materials, more repeatable, reliable, and low-cost synthesis technology of the 2D materials will be further explored, which can pave the way for more widely application of 2D materials not only in OSCs but also in other photovoltaics with high efficiency and stability and finally promote the commercialization of OSCs with mass production.

Funding: This research was funded by Shenzhen Science and Technology Program (Grant No. RCBS20200714114922263).

Institutional Review Board Statement: Not applicable.

Informed Consent Statement: Informed consent was obtained from all subjects involved in the study.

Data Availability Statement: Not applicable.

Conflicts of Interest: The authors declare no conflict of interest.

\section{References}

1. Ameri, T.; Khoram, P.; Min, J. Organic Ternary Solar Cells: A Review. Adv. Mater. 2013, 25, 4245-4266. [CrossRef]

2. Liu, S.H.; You, P.; Li, J.H. Enhanced efficiency of polymer solar cells by adding a high-mobility conjugated polymer. Energy Environ. Sci. 2015, 8, 1463-1470. [CrossRef]

3. Liu, S.H.; Jiang, R.B.; You, P. Au/Ag core-shell nanocuboids for high-efficiency organic solar cells with broadband plasmonic enhancement. Energy Environ. Sci. 2016, 9, 898-905. [CrossRef]

4. Dao, V.D.; Vu, N.H.; Dang, H.L.T. Recent advances and challenges for water evaporation-induced electricity toward applications. Nano Energy 2021, 85, 105979. [CrossRef]

5. Dao, V.D.; Vu, N.H.; Yun, S.N. Recent advances and challenges for solar-driven water evaporation system toward applications. Nano Energy 2020, 68, 104324. [CrossRef]

6. Xie, L.; Song, W.; Ge, J.F. Recent progress of organic photovoltaics for indoor energy harvesting. Nano Energy 2021, 82, 105770. [CrossRef] 
7. Chen, Q.; Zhou, H.P.; Hong, Z.R. Planar Heterojunction Perovskite Solar Cells via Vapor-Assisted Solution Process. J. Am. Chem. Soc. 2014, 136, 622-625. [CrossRef] [PubMed]

8. Liu, S.H.; Lin, S.H.; You, P. Black Phosphorus Quantum Dots Used for Boosting Light Harvesting in Organic Photovoltaics. Angew. Chem. Int. Ed. 2017, 56, 13717-13721. [CrossRef] [PubMed]

9. Hossain, M.A.; Khoo, K.T.; Cui, X. Atomic layer deposition enabling higher efficiency solar cells: A review. Nano Mater. Sci. 2020, 2, 204-226. [CrossRef]

10. Chen, S.S.; Liu, Y.H.; Zhang, L. A Wide-Bandgap Donor Polymer for Highly Efficient Non-Fullerene Organic Solar Cells with a Small Voltage Loss. J. Am. Chem. Soc. 2017, 139, 6298-6301. [CrossRef]

11. Jiang, W.; Ye, L.; Li, X.G. Bay-linked perylene bisimides as promising non-fullerene acceptors for organic solar cells. Chem. Commun. 2014, 50, 1024-1026. [CrossRef]

12. Liu, S.H.; Fu, Y.; Li, G.J. Conjugated Polymer for Voltage-Controlled Release of Molecules. Adv. Mater. 2017, $29,1701733$. [CrossRef]

13. Zhang, A.D.; Li, C.; Yang, F. An Electron Acceptor with Porphyrin and Perylene Bisimides for Efficient Non-Fullerene Solar Cells. Angew. Chem. Int. Ed. 2017, 56, 2694-2698. [CrossRef]

14. Fu, H.T.; Wang, Z.H.; Sun, Y.M. Polymer Donors for High-Performance Non-Fullerene Organic Solar Cells. Angew. Chem. Int. Ed. 2019, 58, 4442-4453. [CrossRef]

15. Li, Z.K.; Jiang, K.; Yang, G.F. Donor polymer design enables efficient non-fullerene organic solar cells. Nat. Commun. 2016, 7, 13094. [CrossRef]

16. Armin, A.; Li, W.; Sandberg, O.J. A History and Perspective of Non-Fullerene Electron Acceptors for Organic Solar Cells. Adv. Energy Mater. 2021, 11, 2003570. [CrossRef]

17. Cui, Y.; Yao, H.F.; Hong, L. Organic photovoltaic cell with $17 \%$ efficiency and superior processability. Natl. Sci. Rev. 2020, 7, 1239-1246. [CrossRef] [PubMed]

18. Li, C.; Zhou, J.D.; Song, J.L. Non-fullerene acceptors with branched side chains and improved molecular packing to exceed $18 \%$ efficiency in organic solar cells. Nat. Energy 2021, 6, 605-613. [CrossRef]

19. Wu, J.N.; Li, G.W.; Fang, J. Random terpolymer based on thiophene-thiazolothiazole unit enabling efficient non-fullerene organic solar cells. Nat. Commun. 2020, 11, 4612. [CrossRef] [PubMed]

20. Zhu, C.; Yuan, J.; Cai, F.F. Tuning the electron-deficient core of a non-fullerene acceptor to achieve over $17 \%$ efficiency in a single-junction organic solar cell. Energy Environ. Sci. 2020, 13, 2459-2466. [CrossRef]

21. Lin, F.; Jiang, K.; Kaminsky, W. A Non-fullerene Acceptor with Enhanced Intermolecular $\pi$-Core Interaction for High-Performance Organic Solar Cells. J. Am. Chem. Soc. 2020, 142, 15246-15251. [CrossRef]

22. Clarke, A.J.; Luke, J.; Meitzner, R. Non-fullerene acceptor photostability and its impact on organic solar cell lifetime. Cell Rep. Phys. Sci. 2021, 2, 100498. [CrossRef]

23. Liu, S.H.; Li, C.Q.; Xu, X.M. Efficiency enhancement of organic photovoltaics by introducing high-mobility curved small-molecule semiconductors as additives. J. Mater. Chem. A 2019, 7, 12740-12750. [CrossRef]

24. Yin, H.; Yan, C.Q.; Hu, H.L. Recent progress of all-polymer solar cells-From chemical structure and device physics to photovoltaic performance. Mater. Sci. Eng. R Rep. 2020, 140, 100542. [CrossRef]

25. Cui, H.Q.; Song, W.; Fanady, B. Flexible ITO-free organic solar cells over 10\% by employing drop-coated conductive PEDOT:PSS transparent anodes. Sci. China Chem. 2019, 62, 500-505. [CrossRef]

26. Fan, X.; Xu, B.G.; Liu, S.H. Transfer-Printed PEDOT:PSS Electrodes Using Mild Acids for High Conductivity and Improved Stability with Application to Flexible Organic Solar Cells. ACS Appl. Mater. Interfaces 2016, 8, 14029-14036. [CrossRef]

27. Yang, Q.; Yu, S.W.; Fu, P. Boosting Performance of Non-Fullerene Organic Solar Cells by 2D g-C $\mathrm{N}_{4}$ Doped PEDOT:PSS. Adv. Funct. Mater. 2020, 30, 1910205. [CrossRef]

28. Fernandez-Arteaga, Y.; Maldonado, J.L.; Nicasio-Collazo, J. Solution processable graphene derivative used in a bilayer anode with conductive PEDOT:PSS on the non-fullerene PBDB-T:ITIC based organic solar cells. Sol. Energy 2021, 225, 656-665. [CrossRef]

29. Wang, J.; Peng, R.X.; Gao, J. $\mathrm{Ti}_{3} \mathrm{C}_{2} \mathrm{~T}_{\mathrm{X}}$ /PEDOT:PSS Composite Interface Enables over $17 \%$ Efficiency Non-fullerene Organic Solar Cells. ACS Appl. Mater. Interfaces 2021, 13, 45789-45797. [CrossRef] [PubMed]

30. Bao, Z.Y.; Liu, S.H.; Hou, Y.D. Hollow Au nanorattles for boosting the performance of organic photovoltaics. J. Mater. Chem. A 2019, 7, 26797-26803. [CrossRef]

31. Hou, C.L.; Yu, H.Z. Modifying the nanostructures of PEDOT:PSS $/ \mathrm{Ti}_{3} \mathrm{C}_{2} \mathrm{~T}_{\mathrm{X}}$ composite hole transport layers for highly efficient polymer solar cells. J. Mater. Chem. C 2020, 8, 4169-4180. [CrossRef]

32. Socol, M.; Preda, N. Hybrid Nanocomposite Thin Films for Photovoltaic Applications: A Review. Nanomaterials 2021, 11, 1117. [CrossRef] [PubMed]

33. Eisner, F.; Seitkhan, A.; Han, Y. Solution-Processed $\operatorname{In}_{2} \mathrm{O}_{3} / \mathrm{ZnO}$ Heterojunction Electron Transport Layers for Efficient Organic Bulk Heterojunction and Inorganic Colloidal Quantum-Dot Solar Cells. Solar RRL 2018, 2, 1800076. [CrossRef]

34. In, S.J.; Park, M.; Jung, J.W. Reduced interface energy loss in non-fullerene organic solar cells using room temperature-synthesized $\mathrm{SnO}_{2}$ quantum dots. J. Mater. Sci. Technol. 2020, 52, 12-19. [CrossRef]

35. Liu, S.H.; Hou, Y.D.; Xie, W. Quantitative Determination of Contribution by Enhanced Local Electric Field, Antenna-Amplified Light Scattering, and Surface Energy Transfer to the Performance of Plasmonic Organic Solar Cells. Small 2018, 14, 1800870. [CrossRef] 
36. Yuan, J.B.; Zhang, X.L.; Sun, J.G. Hybrid Perovskite Quantum Dot/Non-Fullerene Molecule Solar Cells with Efficiency Over 15\%. Adv. Funct. Mater. 2021, 31, 2101272. [CrossRef]

37. Ahmed, E.; Ren, G.Q.; Kim, F.S. Design of New Electron Acceptor Materials for Organic Photovoltaics: Synthesis, Electron Transport, Photophysics, and Photovoltaic Properties of Oligothiophene-Functionalized Naphthalene Diimides. Chem. Mater. 2011, 23, 4563-4577. [CrossRef]

38. Liu, S.H.; Zhang, Y.Y.; Lin, Y. Tailoring the structure and nitrogen content of nitrogen-doped carbon nanotubes by water-assisted growth. Carbon 2014, 69, 247-254. [CrossRef]

39. Ren, G.Q.; Ahmed, E.; Jenekhe, S.A. Nanowires of oligothiophene-functionalized naphthalene diimides: Self assembly, morphology, and all-nanowire bulk heterojunction solar cells. J. Mater. Chem. 2012, 22, 24373-24379. [CrossRef]

40. Wang, Y.F.; Jia, B.Y.; Qin, F. Semitransparent, non-fullerene and flexible all-plastic solar cells. Polymer 2016, 107, 108-112. [CrossRef]

41. Zhao, F.G.; Deng, L.L.; Wang, K. Surface Modification of $\mathrm{SnO}_{2}$ via $\mathrm{MAPbI}_{3}$ Nanowires for a Highly Efficient Non-Fullerene Acceptor-Based Organic Solar Cell. ACS Appl. Mater. Interfaces 2020, 12, 5120-5127. [CrossRef] [PubMed]

42. Butun, S.; Tongay, S.; Aydin, K. Enhanced Light Emission from Large-Area Monolayer $\mathrm{MoS}_{2}$ Using Plasmonic Nanodisc Arrays. Nano Lett. 2015, 15, 2700-2704. [CrossRef]

43. Chen, Y.N.; Sun, Y.; Peng, J.J. Tailoring Organic Cation of 2D Air-Stable Organometal Halide Perovskites for Highly Efficient Planar Solar Cells. Adv. Energy Mater. 2017, 7, 1700162. [CrossRef]

44. Fan, Q.P.; Zhu, Q.L.; Xu, Z. Chlorine substituted 2D-conjugated polymer for high-performance polymer solar cells with $13.1 \%$ efficiency via toluene processing. Nano Energy 2018, 48, 413-420.

45. Ling, H.F.; Liu, S.H.; Zheng, Z.J. Organic Flexible Electronics. Small Methods 2018, 2, 1800070. [CrossRef]

46. Ma, C.Q.; Shen, D.; Ng, T.W. 2D Perovskites with Short Interlayer Distance for High-Performance Solar Cell Application. Adv. Mater. 2018, 30, 1800710. [CrossRef]

47. Das, S.; Pandey, D.; Thomas, J. The Role of Graphene and Other 2D Materials in Solar Photovoltaics. Adv. Mater. 2019, 31, 1802722. [CrossRef] [PubMed]

48. Liu, Z.K.; Lau, S.P.; Yan, F. Functionalized graphene and other two-dimensional materials for photovoltaic devices: Device design and processing. Chem. Soc. Rev. 2015, 44, 5638-5679. [CrossRef]

49. Zhou, H.L.; Wang, C.; Shaw, J.C. Large Area Growth and Electrical Properties of p-Type WSe 2 Atomic Layers. Nano Lett. 2015, 15, 709-713. [CrossRef] [PubMed]

50. Zhang, Y.; Chang, T.-R.; Zhou, B. Direct observation of the transition from indirect to direct bandgap in atomically thin epitaxial $\mathrm{MoSe}_{2}$. Nat. Nanotechnol. 2014, 9, 111-115. [CrossRef]

51. Wu, M.; Zeng, X.C. Bismuth Oxychalcogenides: A New Class of Ferroelectric/Ferroelastic Materials with Ultra High Mobility. Nano Lett. 2017, 17, 6309-6314. [CrossRef] [PubMed]

52. Meng, S.; Wang, J.; Shi, H. Distinct ultrafast carrier dynamics of $\alpha-\mathrm{In}_{2} \mathrm{Se}_{3}$ and $\beta$ - $\mathrm{In}_{2} \mathrm{Se}_{3}$ : Contributions from band filling and bandgap renormalization. Phys. Chem. Chem. Phys. 2021, 23, 24313-24318. [CrossRef] [PubMed]

53. Akinwande, D.; Petrone, N.; Hone, J. Two-dimensional flexible nanoelectronics. Nat. Commun. 2014, 5, 5678. [CrossRef]

54. Nguyen, V.H.; Nguyen, B.S.; Hu, C.C. Novel Architecture Titanium Carbide $\left(\mathrm{Ti}_{3} \mathrm{C}_{2} \mathrm{~T}_{\mathrm{X}}\right)$ MXene Cocatalysts toward Photocatalytic Hydrogen Production: A Mini-Review. Nanomaterials 2020, 10, 602. [CrossRef]

55. Garg, R.; Dutta, N.K.; Choudhury, N.R. Work Function Engineering of Graphene. Nanomaterials 2014, 4, 267-300. [CrossRef]

56. Suh, J.; Park, T.E.; Lin, D.Y. Doping against the Native Propensity of $\mathrm{MoS}_{2}$ : Degenerate Hole Doping by Cation Substitution. Nano Lett. 2014, 14, 6976-6982. [CrossRef]

57. Novoselov, K.S.; Geim, A.K.; Morozov, S.V. Electric field effect in atomically thin carbon films. Science 2004, 306, 666-669. [CrossRef]

58. Eda, G.; Fanchini, G.; Chhowalla, M. Large-area ultrathin films of reduced graphene oxide as a transparent and flexible electronic material. Nat. Nanotechnol. 2008, 3, 270-274. [CrossRef]

59. Eda, G.; Chhowalla, M. Chemically Derived Graphene Oxide: Towards Large-Area Thin-Film Electronics and Optoelectronics. Adv. Mater. 2010, 22, 2392-2415. [CrossRef]

60. Konios, D.; Stylianakis, M.M.; Stratakis, E. Dispersion behaviour of graphene oxide and reduced graphene oxide. J. Colloid Interface Sci. 2014, 430, 108-112. [CrossRef] [PubMed]

61. Huang, X.M.; Liu, L.Z.; Zhou, S. Physical properties and device applications of graphene oxide. Front. Phys. 2020, $15,33301$. [CrossRef]

62. Cao, W.R.; Li, J.; Chen, H.Z. Transparent electrodes for organic optoelectronic devices: A review. J. Photonics Energy 2014, 4, 040990. [CrossRef]

63. Stylianakis, M.M.; Konios, D.; Kakavelakis, G. Efficient ternary organic photovoltaics incorporating a graphene-based porphyrin molecule as a universal electron cascade material. Nanoscale 2015, 7, 17827-17835. [CrossRef] [PubMed]

64. Kakavelakis, G.; Castillo, A.E.D.; Pellegrini, V. Size-Tuning of $\mathrm{WSe}_{2}$ Flakes for High Efficiency Inverted Organic Solar Cells. ACS Nano 2017, 11, 3517-3531. [CrossRef] [PubMed]

65. Wang, H.C.; Lin, Y.C.; Chen, C.H. Hydrogen plasma-treated MoSe 2 nanosheets enhance the efficiency and stability of organic photovoltaics. Nanoscale 2019, 11, 17460-17470. [CrossRef] [PubMed]

66. Yang, W.T.; Ye, L.; Yao, F.F. Black phosphorus nanoflakes as morphology modifier for efficient fullerene-free organic solar cells with high fill-factor and better morphological stability. Nano Res. 2019, 12, 777-783. [CrossRef] 
67. Zhao, Y.; Chen, T.L.; Xiao, L.G. Facile integration of low-cost black phosphorus in solution-processed organic solar cells with improved fill factor and device efficiency. Nano Energy 2018, 53, 345-353. [CrossRef]

68. Jun, G.H.; Jin, S.H.; Lee, B. Enhanced conduction and charge-selectivity by N-doped graphene flakes in the active layer of bulk-heterojunction organic solar cells. Energy Environ. Sci. 2013, 6, 3000-3006. [CrossRef]

69. Fan, X.; Zhang, M.L.; Wang, X.D. Recent progress in organic-inorganic hybrid solar cells. J. Mater. Chem. A 2013, 1, 8694-8709. [CrossRef]

70. Huang, C.W.; Yu, H.Z.; Chen, J.Y. Improved performance of polymer solar cells by doping with $\mathrm{Bi}_{2} \mathrm{O}_{2} \mathrm{~S}$ nanocrystals. Sol. Energy Mater. Sol. Cells 2019, 200, 110030. [CrossRef]

71. Wu, J.X.; Yuan, H.T.; Meng, M.M. High electron mobility and quantum oscillations in non-encapsulated ultrathin semiconducting $\mathrm{Bi}_{2} \mathrm{O}_{2}$ Se. Nat. Nanotechnol. 2017, 12, 530-534. [CrossRef]

72. Li, M.Q.; Dang, L.Y.; Wang, G.G. Bismuth Oxychalcogenide Nanosheet: Facile Synthesis, Characterization, and Photodetector Application. Adv. Mater. Technol. 2020, 5, 2000180. [CrossRef]

73. Fatima, M.J.J.; Navaneeth, A.; Sindhu, S. Improved carrier mobility and bandgap tuning of zinc doped bismuth oxide. RSC Adv. 2015, 5, 2504-2510.

74. Leontie, L.; Caraman, M.; Alexe, M. Structural and optical characteristics of bismuth oxide thin films. Surf. Sci. 2002, 507, 480-485. [CrossRef]

75. Wu, J.X.; Qiu, C.G.; Fu, H.X. Low Residual Carrier Concentration and High Mobility in 2D Semiconducting $\mathrm{Bi}_{2} \mathrm{O}_{2}$ Se. $\mathrm{Nano}_{\text {Lett }}$. 2019, 19, 197-202. [CrossRef]

76. Huang, C.W.; Yu, H.Z. Two-Dimensional $\mathrm{Bi}_{2} \mathrm{O}_{2}$ Se with High Mobility for High-Performance Polymer Solar Cells. ACS Appl. Mater. Interfaces 2020, 12, 19643-19654. [CrossRef]

77. Naguib, M.; Kurtoglu, M.; Presser, V. Two-Dimensional Nanocrystals Produced by Exfoliation of Ti ${ }_{3} \mathrm{AlC}_{2}$. Adv. Mater. 2011, 23, 4248-4253. [CrossRef]

78. Lei, J.C.; Zhang, X.; Zhou, Z. Recent advances in MXene: Preparation, properties, and applications. Front. Phys. 2015, 10, 276-286. [CrossRef]

79. Zhao, Y.; Liu, X.J.; Jing, X. Addition of $2 \mathrm{D} \mathrm{Ti}_{3} \mathrm{C}_{2} \mathrm{~T}_{\mathrm{X}}$ to Enhance Photocurrent in Diodes for High-Efficiency Organic Solar Cells. Solar RRL 2021, 5, 2100127. [CrossRef]

80. Gu, X.; Cui, W.; Li, H. A Solution-Processed Hole Extraction Layer Made from Ultrathin $\mathrm{MoS}_{2}$ Nanosheets for Efficient Organic Solar Cells. Adv. Energy Mater. 2013, 3, 1262-1268. [CrossRef]

81. Gu, X.; Cui, W.; Song, T. Solution-Processed 2D Niobium Diselenide Nanosheets as Efficient Hole-Transport Layers in Organic Solar Cells. Chemsuschem 2014, 7, 416-420. [CrossRef] [PubMed]

82. Koo, D.; Jung, S.; Oh, N.K. Improved charge transport via $\mathrm{WSe}_{2}$-mediated hole transporting layer toward efficient organic solar cells. Semicond. Sci. Technol. 2018, 33, 125020. [CrossRef]

83. Lin, Y.B.; Adilbekova, B.; Firdaus, Y. 17\% Efficient Organic Solar Cells Based on Liquid Exfoliated WS 2 as a Replacement for PEDOT:PSS. Adv. Mater. 2019, 31, 1902965. [CrossRef] [PubMed]

84. Yusoff, A.R.B.; Kim, D.; Schneider, F.K. Au-doped single layer graphene nanoribbons for a record-high efficiency ITO-free tandem polymer solar cell. Energy Environ. Sci. 2015, 8, 1523-1537. [CrossRef]

85. Yu, J.C.; Jang, J.I.; Lee, B.R. Highly Efficient Polymer-Based Optoelectronic Devices Using PEDOT:PSS and a GO Composite Layer as a Hole Transport Layer. ACS Appl. Mater. Interfaces 2014, 6, 2067-2073. [CrossRef]

86. Cheng, X.F.; Long, J.; Wu, R. Fluorinated Reduced Graphene Oxide as an Efficient Hole-Transport Layer for Efficient and Stable Polymer Solar Cells. ACS Omega 2017, 2, 2010-2016. [CrossRef] [PubMed]

87. Cheng, J.Q.; Zhang, H.; Zhao, Y. Self-Assembled Quasi-3D Nanocomposite: A Novel p-Type Hole Transport Layer for High Performance Inverted Organic Solar Cells. Adv. Funct. Mater. 2018, 28, 1706403. [CrossRef]

88. Zheng, X.; Zhang, H.J.; Yang, Q.L. Solution-processed Graphene-MoS 2 heterostructure for efficient hole extraction in organic solar cells. Carbon 2019, 142, 156-163. [CrossRef]

89. Wang, J.M.; Yu, H.Z.; Hou, C.L. Solution-Processable 2D $\alpha-\mathrm{In}_{2} \mathrm{Se}_{3}$ as an Efficient Hole Transport Layer for High-Performance and Stable Polymer Solar Cells. Solar RRL 2020, 4, 1900428. [CrossRef]

90. Wang, J.M.; Yu, H.Z.; Hou, C.L. Solution-Processable PEDOT:PSS: $\alpha-\mathrm{In}_{2} \mathrm{Se}_{3}$ with Enhanced Conductivity as a Hole Transport Layer for High-Performance Polymer Solar Cells. ACS Appl. Mater. Interfaces 2020, 12, 26543-26554. [CrossRef] [PubMed]

91. Huang, Y.J.; Chen, H.C.; Lin, H.K. Doping ZnO Electron Transport Layers with $\mathrm{MoS}_{2}$ Nanosheets Enhances the Efficiency of Polymer Solar Cells. ACS Appl. Mater. Interfaces 2018, 10, 20196-20204. [CrossRef]

92. Chen, S.; Small, C.E.; Amb, C.M. Inverted Polymer Solar Cells with Reduced Interface Recombination. Adv. Energy Mater. 2012, 2, 1333-1337. [CrossRef]

93. Lin, S.H.; Liu, S.H.; Yang, Z.B. Solution-Processable Ultrathin Black Phosphorus as an Effective Electron Transport Layer in Organic Photovoltaics. Adv. Funct. Mater. 2016, 26, 864-871. [CrossRef]

94. Konios, D.; Kakavelakis, G.; Petridis, C. Highly efficient organic photovoltaic devices utilizing work-function tuned graphene oxide derivatives as the anode and cathode charge extraction layers. J. Mater. Chem. A 2016, 4, 1612-1623. [CrossRef]

95. Zheng, D.; Huang, W.; Fan, P. Preparation of Reduced Graphene Oxide:ZnO Hybrid Cathode Interlayer Using In Situ Thermal Reduction/Annealing for Interconnecting Nanostructure and Its Effect on Organic Solar Cell. ACS Appl. Mater. Interfaces 2017, 9 , 4898-4907. [CrossRef] [PubMed] 
96. Pan, F.; Sun, C.K.; Li, Y.F. Solution-processable n-doped graphene-containing cathode interfacial materials for high-performance organic solar cells. Energy Environ. Sci. 2019, 12, 3400-3411. [CrossRef]

97. Xing, W.; Ye, P.; Lu, J. Tellurophene-based metal-organic framework nanosheets for high-performance organic solar cells. J. Power Sources 2018, 401, 13-19. [CrossRef]

98. Hou, C.L.; $\mathrm{Yu}, \mathrm{H} . \mathrm{Z} . \mathrm{ZnO} / \mathrm{Ti}_{3} \mathrm{C}_{2} \mathrm{~T}_{\mathrm{X}}$ monolayer electron transport layers with enhanced conductivity for highly efficient inverted polymer solar cells. Chem. Eng. J. 2021, 407, 127192. [CrossRef]

99. Yusoff, A.; Lee, S.J.; Shneider, F.K. High-Performance Semitransparent Tandem Solar Cell of 8.02\% Conversion Efficiency with Solution-Processed Graphene Mesh and Laminated Ag Nanowire Top Electrodes. Adv. Energy Mater. 2014, 4, 1301989. [CrossRef]

100. Wang, B.Y.; Lee, E.S.; Oh, Y.J. A silver nanowire mesh overcoated protection layer with graphene oxide as a transparent electrode for flexible organic solar cells. RSC Adv. 2017, 7, 52914-52922. [CrossRef]

101. Ricciardulli, A.G.; Yang, S.; Feng, X.L. Solution-Processable High-Quality Graphene for Organic Solar Cells. ACS Appl. Mater. Interfaces 2017, 9, 25412-25417. [CrossRef] [PubMed]

102. Ricciardulli, A.G.; Yang, S.; Wetzelaer, G. Hybrid Silver Nanowire and Graphene-Based Solution-Processed Transparent Electrode for Organic Optoelectronics. Adv. Funct. Mater. 2018, 28, 1706010. [CrossRef]

103. Jung, S.; Lee, J.; Seo, J. Development of Annealing-Free, Solution-Processable Inverted Organic Solar Cells with N-Doped Graphene Electrodes using Zinc Oxide Nanoparticles. Nano Lett. 2018, 18, 1337-1343. [CrossRef] [PubMed]

104. Koo, D.; Jung, S.; Seo, J. Flexible Organic Solar Cells Over 15\% Efficiency with Polyimide-Integrated Graphene Electrodes. Joule 2020, 4, 1021-1034. [CrossRef]

105. Tang, H.H.; Feng, H.R.; Wang, H.K. Highly Conducting MXene-Silver Nanowire Transparent Electrodes for Flexible Organic Solar Cells. ACS Appl. Mater. Interfaces 2019, 11, 25330-25337. [CrossRef] [PubMed]

106. Jinno, H.; Fukuda, K.; Xu, X. Stretchable and waterproof elastomer-coated organic photovoltaics for washable electronic textile applications. Nat. Energy 2017, 2, 780-785. [CrossRef] 